San Jose State University

SJSU ScholarWorks

Master's Theses

Master's Theses and Graduate Research

Fall 2009

\title{
Investigation of the origins of prospective memory under various cognitive loads.
}

Sarah V. Ligda

San Jose State University

Follow this and additional works at: https://scholarworks.sjsu.edu/etd_theses

\section{Recommended Citation}

Ligda, Sarah V., "Investigation of the origins of prospective memory under various cognitive loads." (2009). Master's Theses. 4008.

DOI: https://doi.org/10.31979/etd.jwzr-3veh

https://scholarworks.sjsu.edu/etd_theses/4008

This Thesis is brought to you for free and open access by the Master's Theses and Graduate Research at SJSU ScholarWorks. It has been accepted for inclusion in Master's Theses by an authorized administrator of SJSU ScholarWorks. For more information, please contact scholarworks@sjsu.edu. 


\section{NOTE TO USERS}

\section{This reproduction is the best copy available.}




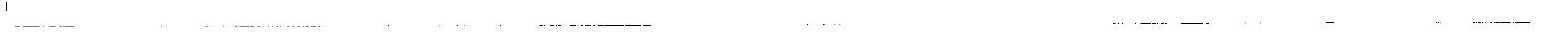




\title{
INVESTIGATION OF THE ORIGINS OF
}

PROSPECTIVE MEMORY UNDER VARIOUS COGNITIVE LOADS

\author{
A Thesis \\ Presented to \\ The Faculty of the Department of Psychology \\ San José State University
}

In Partial Fulfillment

of the Requirements for the Degree

Master of Arts

by

Sarah V. Ligda

December 2009 
UMI Nụmber: 1484366

All rights reserved

INFORMATION TO ALL USERS

The quality of this reproduction is dependent upon the quality of the copy submitted.

In the unlikely event that the author did not send a complete manuscript and there are missing pages, these will be noted. Also, if material had to be removed, a note will indicate the deletion.

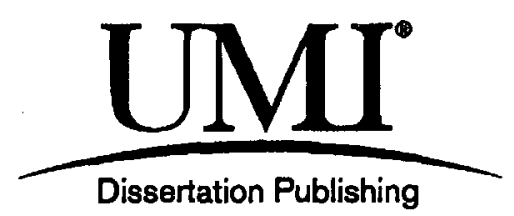

UMI 1484366

Copyright 2010 by ProQuest LLC.

All rights reserved. This edition of the work is protected against unauthorized copying under Title 17, United States Code.

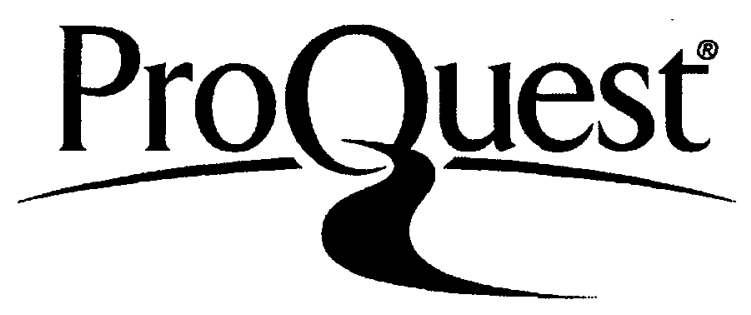

ProQuest LLC

789 East Eisenhower Parkway

P.O. Box 1346

Ann Arbor, MI 48106-1346 
(C) 2009

Sarah V. Ligda

ALL RIGHTS RESERVED 


\section{SAN JOSE STATE UNIVERSITY}

The Undersigned Thesis Committee Approves the Thesis Titled INVESTIGATION OF THE ORIGINS OF

PROSPECTIVE MEMORY UNDER VARIOUS COGNITIVE LOADS

by

Sarah V. Ligda

APPROVED FOR THE DEPARTMENT OF PSYCHOLOGY

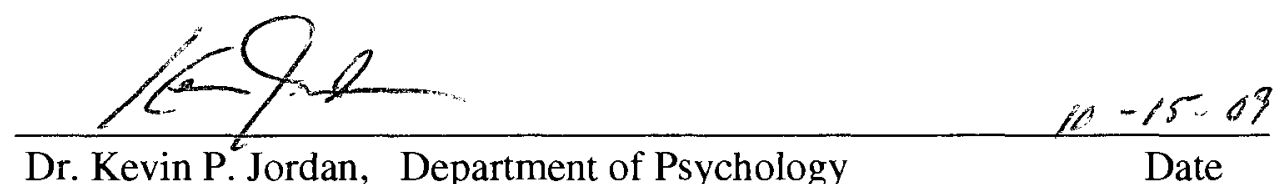

Dr. Kevin P. Jordan, Department of Psychology Date

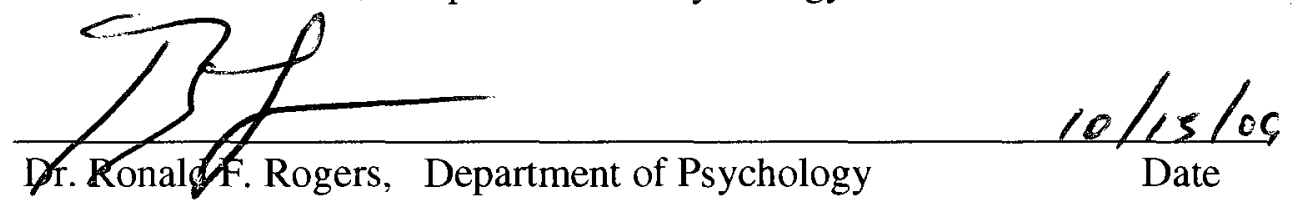

Dr. Sean Laraway, Departmet of Psychology $\frac{10-15-09}{\text { Date }}$

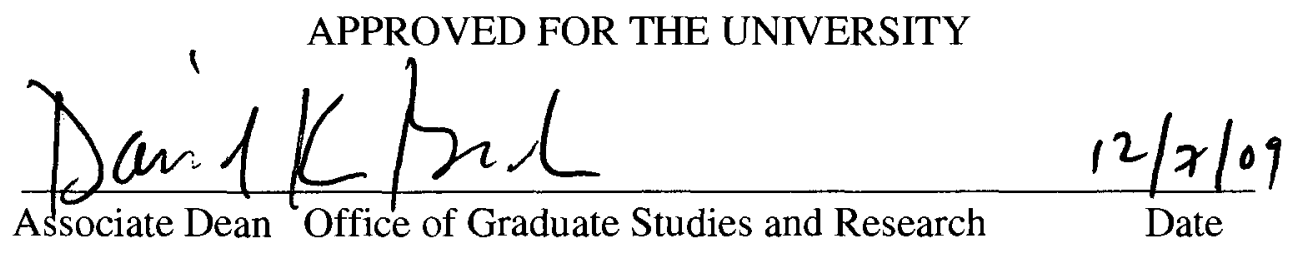




\section{ABSTRACT \\ INVESTIGATION OF THE ORIGINS OF \\ PROSPECTIVE MEMORY UNDER VARIOUS COGNITIVE LOADS \\ by Sarah V. Ligda}

This thesis examined if prospective memory ability was selected for increased survival skills under a specific cognitive load level. Two-hundred seventy San Jose State University students under the age of 35 participated in this study that manipulated prospective memory type and cognitive load level and that employed a novel ratio scale measurement. Prospective memory performance was found to be more expeditious in the survival-based condition, $F(1,176)=5.41, p=.02$ and high cognitive load condition, $F(1$, $176)=5.41, p=.02$ for those that execute prospective memory tasks directly after recalling those tasks at the appropriate time. No difference was found in either the task type or cognitive load level for those whose prospective memory execution was delayed with respect to recall. 


\section{ACKNOWLEDGEMENTS}

This work is the culmination of the contributions of many individuals, all of whom I owe my deepest gratitude. I would like to thank my committee members, Dr. Kevin P. Jordan, Dr. Sean Laraway, and Dr. Ronald F. Rogers, for their academic advice, guidance, and patience throughout the course of this thesis and my graduate student career. I would also like to express my appreciation to my San Jose State cohort, Ames colleagues, and friends for their willingness to listen and provide academic and emotional support. Lastly, I am forever grateful to my family, especially Margaret and Steven, for their moral support and love throughout this process. 


\section{TABLE OF CONTENTS}

SECTION

PAGE

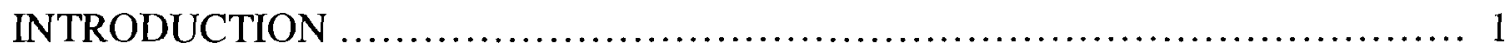

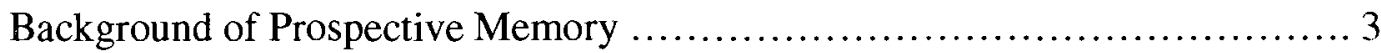

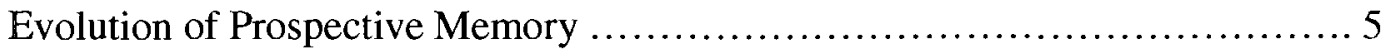

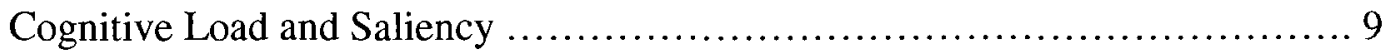

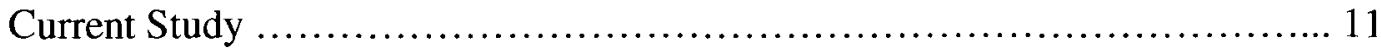

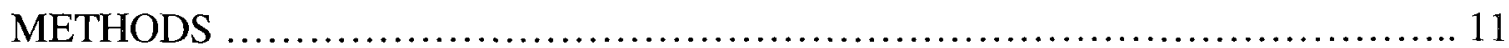

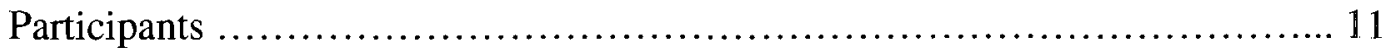

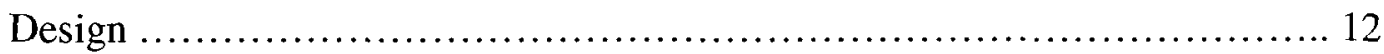

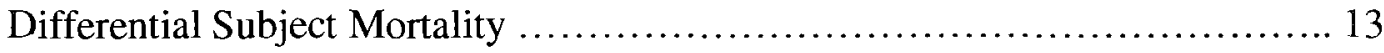

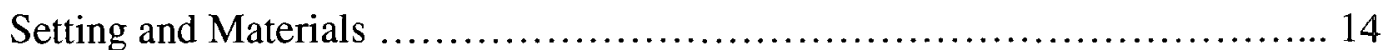

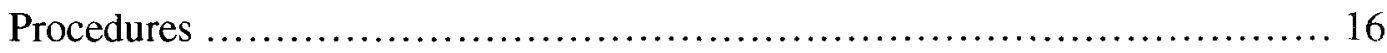

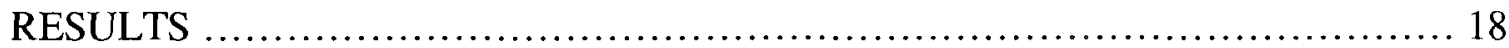

Full Set Demographics ............................................. 19

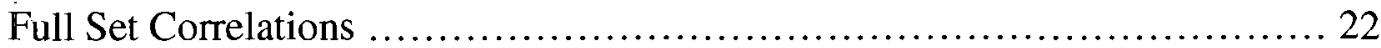

Full Set Inferential Statistics ........................................ 22

Reason for Excluding Participants ....................................... 25

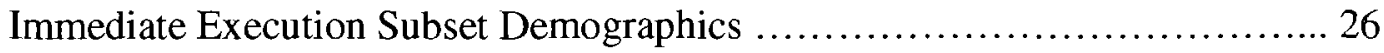

Immediate Execution Subset Correlations .................................. 29

Immediate Execution Subset Inferential Statistics ......................... 29

Excluded Participants .................................................... 32 
Delayed Execution and Additional Cued Subset Analyses

Frequency of Failed Execution ........................................ 37

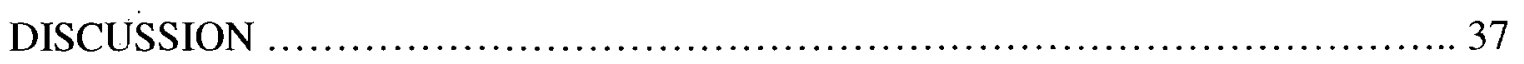

Cognitive Load Difficulty ............................................ 39

Prospective Memory Ratio Scale Method .................................. 40

Deception ............................................................ 41

Improper Execution and Frequency of Failed Execution ..................... 42

Issues and Future Studies ................................................ 43

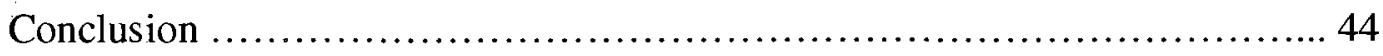

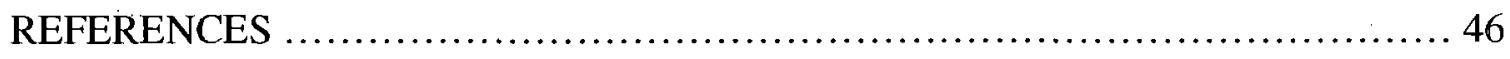

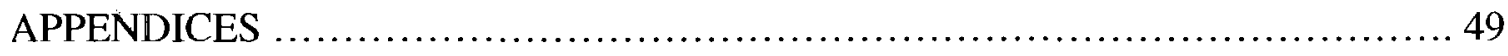

Appendix A: Demographics questionnaire administered to participants ........ 49

Appendix B: Facial attractiveness rating scale presented to all female participants in the survival-based prospective memory task condition ... 50

Appendix C: Facial attractiveness rating scale presented to all male participants in the survival-based prospective memory task condition ... 51

Appendix D: Film preference rating scale presented to all participants

in the cultural-based prospective memory task condition ................52

Appendix E: Sample of a visuospatial task series presented to participants ...... 53

Appendix F: Letter of approval from human subjects institutional

review board 54 


\section{LIST OF TABLES}

TABLE

PAGE

1. Percentages, Means, and Standard Deviations of Variables for the Full Set of Participants

2. Pearson Correlation Coefficients Among Variables, and Means and Standard Deviations for the Full Set of Participants

3. Percentages, Means, and Standard Deviations of Variables of Participants

Who Immediately Reminded the Proctor Concerning the Prospective

Memory Task

4. Pearson Correlation Coefficients Among Variables, and Means and Standard Deviations of Participants Who Immediately Reminded the Proctor Concerning the Prospective Memory Task 28

5. Percentages, Means, and Standard Deviations of Participants

Who Delayed in Reminding the Proctor Concerning the Prospective

Memory Task 35

6. Pearson Correlation Coefficients Among Variables, and Means and Standard Deviations of Participants Who Delayed in Reminding the Proctor Concerning the Prospective Memory Task 


\section{LIST OF FIGURES}

FIGURE PAGE

1. Line Graph of Mean Number of Seconds Elapsed as a Function of Cultural and Survival Tasks and Level of Cognitive Load (All Participants) ............ 24

2. Line Graph of Mean Number of Seconds Elapsed as a Function of Cultural and Survival Tasks and Level of Cognitive Load (Immediate Execution

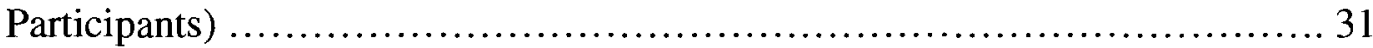




\section{Introduction}

Evolutionary theory states that species change through a controlled selection of mutations over an extensive time period (Gaulin \& McBurney, 2001). Genetic mutations and sexual recombinations create variability in each species; those individuals that contain mutations resulting in adaptive traits and features that allow a greater ability to survive and reproduce within their environment have an inherent advantage over similar individuals that do not have those adaptations. Because many species compete for resources within their environment, these adaptations give those individuals a greater ability to reproduce and pass on their genes (including the genetic mutations) to their offspring while other individuals die off.

Evolved features emerge through several different methods. An adaptation is a feature that is selected due to its fitness-enhancing capabilities at the time of its formation: "an adaptation may be defined as an inherited and reliably developing characteristic that came into existence as a feature of a species through natural selection because it helped to directly or indirectly facilitate reproduction during the period of its evolution" (Buss, Haselton, Shackelford, Bleske, \& Wakefield, 1998, p. 535). For a feature to have adapted, it must be useful at the time of its development. Two other methods are exaptations and spandrels. An exaptation is a feature that arose for a specific function that aided in survival and reproduction, but later provided another function. According to Buss et al. (1998), bird's feathers may have originally adapted for the function of thermoregulation, but after time they might have served a function in flight. A spandrel is a feature that arose for a specific function that developed after another 
adapted feature as a by-product. Gould (1991) states that there are thousands of spandrels, including religion and reading, that resulted as by-products of human's large brain structures and cognitive abilities.

Many adaptations in humans gave rise to our complex cognitive abilities, including memory. In many species, memory is a broad ability that allows organisms to encode, retain, and retrieve many types of information to assist in various types of behaviors and other abilities. Many types of memory appear to be exclusive to humans. One of these exclusive types is prospective memory (Tulving, 2002), which is defined as memory to perform specific tasks at some pre-determined point in the future (Einstein \& McDaniel, 1996). On many occasions, tasks placed in prospective memory are not executed at the correct pre-determined time. Researchers have searched for reasons for prospective memory failures for approximately three decades without any extensive leaps in understanding. Perhaps part of the answer lies in the classification of the memory tasks. Like most other evolved features, many subsystems of memory were selected for due to their ability to provide greater survival skills (Klein, Cosmides, Tooby, \& Chance, 2002).

If prospective memory adapted to aid in survival abilities, this feature might perform better under certain types of memory tasks, specifically survival-based memory tasks when compared to other tasks (all other factors being equal). However, if prospective memory is an exaptation or a spandrel that arose after another adapted feature, performance would more likely be approximately equal regardless of the classification of the task. This is because the feature did not adjust to one particular 
function (survival-enhancing), but emerged through another method. The current study will address whether prospective memory was adapted for increased survival skills rather than a fortuitous ability that formed due to the evolution of human cognition and functions more dynamically according to individual needs.

\section{Background of Prospective Memory}

To what memory subsystem does prospective memory belong? Most researchers today (Einstein \& McDaniel, 1996; Suddendorf \& Busby, 2005; Woods, et al., 2008) agree that prospective memory belongs within the episodic memory system. Episodic memory is memory of events related to an individual's experience. Others argue that prospective memory belongs to a broader executive functioning category (Winograd, 1988) due to other constructs it requires, such as motivation, attention, compliance, and vigilance.

Two broad types of prospective memory have been studied: event-based and time-based. Event-based prospective memory involves performing an action when a specific future event takes place (Einstein \& McDaniel, 1996, p. 167); for example, remembering to take medication directly after dinner. In contrast, time-based prospective memory requires an individual to perform a specific action at a specific pre-determined time in the future (Einstein \& McDaniel, 1996, p. 167); for example, remembering to take a medication at exactly $6 \mathrm{pm}$. Studies suggest that because event-based prospective memory is connected to a future event, it is more salient and therefore usually easier to remember than time-based (Marsh, Hicks, Cook, \& Mayhorn, 2007; Einstein \& McDaniel, 1996). It can be further suggested that our ancestors primarily used event- 
based prospective memory because most of our archeological history was spent without clocks (Barnard, 2004). Even though hunter-gatherers most likely used circadian rhythms and methods similar to sun dials as assistance in time-telling, these methods would likely be categorized under event-based such as sun-rise and physiological processes, such as fatigue. However, because there is little research investigating the connection between evolution and prospective memory, this deduction has not been investigated.

Einstein and McDaniel (1996) state that there are a wide range of tasks and intentions that fall under the prospective memory term; some tasks are habitual, and as the name implies, need to be executed more than once over a period of time, such as taking antibiotics three times a day for a week as prescribed. Other tasks utilize external cues, such as placing a medication bottle near the bed as a reminder to take medication before bedtime. Another type is internally-cued that is executed without any external reminders. Also, prospective memory can be long-term, such äs remembering to return a library book in two weeks; or short-term, such as remembering to turn off the stove once a pot of water boils. Typically, prospective memory tasks fall under several of these categories.

Because of the spectrum of different types and related constructs, researchers have faced a difficult methodological task of operationalizing and directly measuring prospective memory in an experimental setting that contains high external validity. A review of dozens of recent empirical prospective memory studies (e.g., Marsh, Hicks, Cook, \& Mayhorn, 2007; Rendell \& Craik, 2000; Zimmerman \& Meier, 2006) that 
attempt to utilize a direct method has not yielded any widely-implemented dependent measure, but an assortment of unique techniques for measuring different types of prospective memory performance. One measure utilized occasionally in prospective memory pharmacological research is a subtest of the Rivermeäd Behavioral Memory Test (RMBT), developed by Wilson, Cockburn and Baddeley (1985). This subtest, named Appointment (R4), is one in which the participant is required to remind the proctor to ask when the next meeting will be held at the sound of an alarm after 20 minutes. This subtest is a direct measurement of prospective memory performance, and is suited for examining short-term prospective memory performance in a controlled laboratory setting. Evolution of Prospective Memory

The research of prospective memory's evolutionary origins is highly fragmented, presumably because prospective memory's empirical research is relatively recent compared with other forms of memory. Furthermore, no studies to date examine whether prospective memory should be considered an adaptation, exaptation, or spandrel. However, many studies indirectly suggest that prospective memiory and survival are linked. Prospective memory performance and age have a strong correlation; prospective memory performance follows an inverted U-shaped function with increasing age, with adolescents and young adults performing high, and children and older adults performing low (Zimmermann \& Meier, 2006). Many other studies have found that prospective memory performance declines significantly after the age of 35 to 40 years (Marsh., et al., 2007; Kliegal, Martin \& Moor, 2003; Rendell \& Craik, 2000). This suggests that prospective memory performance correlates with young adulthood and peak fertility. 
Even though healthy males can reproduce most of their adult lives, androgen levels peak in young adulthood resulting in an increased sexual drive; after the age of 40 , testosterone levels decreases by as much as 40\% (Davidson, Chen, Crapo, Gray, Greenleaf, \& Catania, 1983). Similarly, female's peak fertility age is also young adulthood, specifically mid-to late 20s (Soules et al., 2001).

Throughout millions of years of hunter-gatherer communities in the Mesolithic period, increased survival skills were likely needed in young adulthood to find mates, protection, food, and to care for young (Barnard, 2004). Those individuals who were able to efficiently remember future survival needs would have an inherent advantage to thrive and reproduce within their environment compared with those who could not. These survival needs suggest that prospective memory should have adapted as a function in survival enhancement. However, this prospective memory performance correlation could also be due to a number of other factors such as brain mass, as general cognition also follows this same inverted U-shape function with respect to age (Zimmermann \& Meier, 2006).

The crux of prospective memory is future needs and desires. "The individual identifies with the anticipated future self and makes this imaginary future self's goals its own. We can anticipate our future needs and hence act now to secure not just the present, but also future survival" (Suddendorf \& Busby, 2005, p. 118). Suddendorf and Busby (2005) found that many 3 to 5 year-old children anticipated futüre needs when told that they were being placed in a room without toys; a large majority of the participants decided to bring a toy to the empty room. The high saliency of this task indicates that 
relative importance and relevance are factors in envisioning future situations within children. Although this study did not directly measure prospective memory, the concept of anticipating future needs and desires is closely linked with prospective memory. However, developmental issues arise when using children as studies suggest that certain types of memory are not fully developed within children (Zimmerman \& Meier, 2006).

An individual can only cognitively encode, retain and later retrieve a fraction of external information that he or she perceives. From an evolutionary perspective, external information that increases the probability of an individual's likelihood to survive and reproduce would most likely fall into that fraction (Nairne, Thompson \& Pandeirada, 2007; Ohman \& Mikena, 2001). The results of Nairne et al.'s (2007) study suggest that survival processing increases working memory retention when compared to a control condition. In the first (within-subject) and second (between-subject) experiment, participants were asked to imagine themselves in one of two scenarios. The first scenario was survival-based, in which the participants imagined themselves deserted in the grasslands of a strange land for several months without any basic survival needs. They also imagined that they attempted to find food, water, shelter and protection from predators. The second scenario was moving-based, in which the participants imagined moving to a foreign country and finding a residence and transport for belongings. After imagining themselves in one of the two scenarios, participants rated the importance and relevance of a list of words in regard to the scenario, and then were asked to recall the same list of words a few minutes later after a distraction task. The third experiment replicated the second, but used word recognition instead of word recall. In all three 
experiments, the survival condition increased word recall (or recognition) when compared with the moving condition. The fourth experiment used a self-reference condition instead of the moving scenario, such as "does this word describe you?" The results of the fourth experiment also produced a higher percentage of word recall within the survival condition than in the self-reference condition.

The results of this study suggest that when healthy young adults are faced with a survival task, there is a noticeable increase in working memory encoding, retention and/or retrieval when compared to other external or internal tasks. However, the results of this study might be due to reasons other than only the survival aspect of the experiment. One confound might be the quality, sense of urgency and importance of the processing in the survival condition that the other conditions lacked: when compared to the moving or self-reference condition, the participants in the survival condition seemed to be given more detailed descriptions and were told they needed to find food and protection. Furthermore, although Nairne et al. employed a self-relevant condition as a mnemonic strategy as an attempt to increase retention, comparing an external survival condition with an internal self-relevance condition in a working memory task may produce incomparable data. These two conditions might be too dissimilar to compare to one another.

Emerging research is beginning to show that an increase of retrieval rates within episodic memory can be linked to survival tasks (Suddendorf \& Busby, 2005; Nairne, et al., 2007), suggesting that this ability might have adapted to aid in survival. However, perhaps this is purely a relevance phenomenon. High relevance of information could be 
the cause of high encoding, retention, recall and execution of prospective memory tasks rather than whether a condition is survival-based. The literature is lacking a prospective memory study that contains a survival condition with an equally relevant and important external condition. A survival condition paired with a cultural condition that is approximately equal in relevance and importance (if chosen meticulously based on the participant's general environment) may assist in uncovering whether prospective memory performance was adapted to increase our survival skills, or arose at a later point as a exaptation or spandrel - a more dynamic process of cognition depending on each individual's changing needs.

\section{Cognitive Load and Saliency}

According to Gaulin and McBurney (2001), information is differentially processed depending on attention, frequency, importance, motivation, emotion, and many other factors. Some information is not encoded, some is encoded but later forgotten, some information is retained and later retrieved for a lifetime. Humans are designed to process information systematically based on needs within their environment. Similarly, Sweller (2003) stated that cognition evolved to systematically select information that would lead to perpetuation of the individual's genes. Information is brought into working memory through either sensory information or through long-term memory to aid in the decision-making processes that guide behavior. Any information in working memory that leads to different behaviors will be tested against the environment and consequently either be kept in long-term memory or be forgotten. 
Iran-Nejad, Marsh, and Clements (1992) argue that cognition evolved to help solve survival problems specifically within high cognitive load situations - situations that require a large amount of attention and concentration (Sweller, 2003). While performing high cognitive load tasks, information that would aid in solving survival problems is processed as more essential than other information to remain salient in memory. If this model extends to prospective memory performance, higher emphasis should be placed on remembering survival-based tasks when performing a high cognitive load task in which attentional resources are limited. In contrast, less emphasis should be placed on remembering non-survival-based tasks. In keeping with this model, perhaps in the absence of a high cognitive load, prospective memory performance returns to a baseline level in which tasks of similar relevance and importance are approximately equally emphasized to be remembered. However, research has yet to investigate this theory. According to Enns (2004), visual areas of the brain have more neurons to recognize and process human faces compared with other items. Lewis, Kagan, and Kalafat's (1966) seminal study in which infants fixated longer when presented with photographs of human faces than other objects suggest that these visual face-recognition neurons are evolutionarily selected to be more salient than other visual objects. This theory was later refined by Pascalis, et al. (2002), who found that 6-month old infants discriminate between individual non-human and human primate faces until the age of 10 months old, when they can only discriminate within their own species. This suggests that human social interaction might be a large factor in shaping infant's basic social skills. Conversely, Gaulin and McBurney (2001) suggest that face recognition is an 
evolutionarily-selected adaptation to aid in processing information in complex social situations in which examining potential mates and recognizing friends and family members are vital in survival and reproduction. A visual facial cue might further aid in the performance of a survival-based prospective memory task when compared to an equally relevant and important cultural-based task with a different applicable visual cue. Because viewing human faces elicits greater saliency when compared with other visual objects (Enns, 2004; Gaulin \& McBurney, 2001; Lewis, Kagan, \& Kalafat, 1966), a facial cue should assist in encoding, retention, recall and execution of a prospective memory task.

\section{Current Study}

The question posed by the gaps in the literature is whether prospective memory performance adapted to aid in survival skills. If this is true, recall and immediate execution of an event-based, externally-cued, short-term prospective memory task should be more expeditious when the task is survival-based compared to when a task is culturalbased within a high cognitive load. Many studies support this claim, but none have directly evaluated this.

\section{Methods}

\section{Participants}

This study recruited a convenience sample of 270 San Jose State University students from the psychology research subject pool. Participants were restricted to neurologically healthy adults with normal or corrected to normal vision under the age of 35 due to a decrease in prospective memory performance for those above the age of 35 
(Zimmerman \& Meier, 2006). The participants had a mean age of 20.38 years (SD $=$ 2.84), $70.0 \%$ were female, $30.4 \%$ were Caucasian, $44.4 \%$ were freshman, $37.8 \%$ were psychology majors, had a mean GPA of 3.15, had a mean busyness self-report of 5.16 and stress self-report of 4.82 (both on a 7-point scale, 7 signifying extremely busy/stressed within the past month), on average internally reminded themselves 2.09 times within the 30 -minute cognitive load task, and $66.7 \%$ immediately executed the prospective memory task after recall. Because a medium effect size was anticipated, this study needed at least 180 participants according to Cohen (1992) for a power of .80 with an alpha level of .05 . Informed consent was documented with a signature and date by each participant after he or she read the information about the study, understood, and agreed to be in the study.

Design

This study was a 2 (prospective memory task) x 2 (cognitive load level) betweensubjects factorial design examining recall and execution on an event-based, short-term, externally-cued prospective memory task.

The two levels of the prospective memory condition were as follows: the survival prospective memory condition was operationalized as a facial attractiveness rating scale; the cultural prospective memory condition was operationalized as a film preference rating scale. One of the two rating scales was presented to the participant at the beginning of the study to manipulate visual salience and increase prospective memory encoding. The participants were told to remind the proctor to administer the rating scale after the cognitive load task. 
The two levels of the cognitive load condition were operationalized as the difficulty of the cognitive task performed for 30 minutes between the prospective memory encoding and the five-minute window of opportunity to recall and immediately execute the prospective memory task. In the high cognitive load condition, the participants performed a series of timed complex mental visuospatial rotation tasks. This has proved to be an involving, high cognitive load task when performed without distractions (Pillay, 1994). In the low cognitive load condition, the participants performed a series of timed simple mental visuospatial rotation tasks.

The dependent variable was prospective memory performance. Prospective memory performance was operationalized as recall and immediate execution lapse time: the time between completion of the cognitive load task and the participant recalling the reminder (and immediately executing after that recall) for the proctor to administer the specific rating scale. Therefore, the dependent variable was a ratio measurement from 0 to 300 seconds.

\section{Differential Subject Mortality}

Each participant was randomly assigned to the four conditions, with two constraints. The first constraint was that each participant was required to follow the proctor's instructions for that participant's data to be included in the main analysis. More specifically, each participant was required to execute the prospective memory task immediately after recalling that task when the cognitive load tásk was complete. This constraint was necessary to obtain an accurate ratio measurement of the expeditiousness of prospective memory performance. The second constraint was to obtain an equal 
number of participants in each group for data analysis. This resulted in differential subject mortality: the number of excluded data points varied across the four groups. These excluded data will be analyzed in the results section for any significant differences from the set of participants that followed the instructions.

\section{Setting and Materials}

The setting was a quiet, well-ventilated room on San Jose State University's campus containing a laptop with a 17 -inch monitor placed on a desk. The room was adequately lit and contained a comfortable chair.

Materials used were a consent form, a series of computerized visuospatial tasks, and a demographic questionnaire (see appendices) for each participant. In addition, one of three packets of $8 \frac{1 / 2}{2}$ inch by 11 inch white blank paper (15 pages) was used for each participant. The first two packets had a front page entitled "Facial Attractiveness Rating Scale" with a color photograph beneath the title of an opposite gendered (in relation to each participant) attractive young adult, and a 7-point Likert-type scale beneath the photograph. Each facial image was adapted from DeBruine (2004) of composite faces rated to be attractive. To create ethnic-neutral faces, the face presented to the participant was synthetically blended for ethnicity so that the final image was a composite of several different images (see Appendix B \& C). The third packet had a front page entitled "Film Preference Rating Scale" with a color photograph beneath the title of a documentary movie poster entitled "Travelling Birds" and a 7-point Likert-type scale beneath the photograph (see Appendix D). 
The materials used in the cognitive load conditions were a series of visuospatial tasks rated on complexity (high or low) and average processing times (in seconds) by Bethell-Fox and Shepard (1988) (see Appendix E). The task was computerized, with black 18-font Times New Roman font text on a white background. Participants were approximately 24 inches from the computer monitor. The task was to correctly discriminate between three matrices of different patterns of 9 black and white boxes of varying complexity rotated either 90 or 180 degrees clockwise or counterclockwise from the matrix's original position. Each series contained the original matrix position and three possible choices below the original matrix, with one correct choice. The participant's task was to choose from these three possible choices by pressing a keyboard key that corresponded to each choice. In the high cognitive load condition, each series appeared for 5 seconds before a correct (green coloring) or incorrect (red coloring) screen appeared. The participant's selection corresponded to the correct/incorrect screen. If no selection was made, an incorrect screen appeared. Following the correct/incorrect screen, the next series automatically appeared on the screen. Depending on the complexity and rotation of the original matrix, the time given to solve each series ( 5 seconds) was 0 to 7 seconds less than the average processing time rated by Bethell-Fox and Shepard (1988) to increase cognitive load. In the low cognitive load condition, each series appeared for 9 seconds before the next series automatically appeared on the screen. The time given to solve each series ( 9 seconds) was approximately 5 seconds more than the average processing time rated by Bethell-Fox and Shepard (1988) to decrease cognitive load. Lastly, a computerized alarm and stopwatch were used to time the dependent measure. 


\section{Procedures}

After arriving at the lab, the participant was instructed to sit in a comfortable chair facing a desk in a quiet room, leaving any personal belongings outside the room to prevent the participant from writing down cues for the prospective memory task and from becoming distracted from the cognitive load task. Each participant first read and signed a consent form and filled out a second sheet to obtain partial credit in his or her respective class. The proctor then started the computerized mental rotation instructions for each participant that introduced the mental rotation task, explained how to use the keyboard to select the correct choice in each series, that each series was timed ( 5 or 9 seconds), and that encouraged the participant to perform well to yield accurate results for the study.

The prospective memory task condition was operationalized as the proctor instructing the participant directly before the 30-minute cognitive load task to remind the proctor to administer the facial attractiveness or film preference rating scale at the end of the cognitive load task. This is methodologically similar to the Rivermead Behavioral Memory Test's Attention $(R 4)$ subtest, which has an internal consistency reliability measure of Cronbach's $\alpha=.683$ and test-retest reliability measure of Pearson's $r=.823$ (Efklides, Yiultsi, Kangellidou, Kounti, Dina, \& Tsolaki, 2002).

After the instructions were complete, the proctor asked the participant if he or she had any questions concerning the mental rotation task. Subsequently, the proctor casually instructed the participant to remind the proctor to administer the rating scale at the end of the cognitive load task: "Actually, can you remind me to give you this rating scale when the mental rotation task is over? Just remind me as soon as you remember. 
Thanks." The proctor presented a packet of the rating scale to the participant with the specific rating scale type (facial attractiveness or film preferenice) written across the front cover with an image of the type underneath (see appendices). The proctor was certain that the participant viewed the image underneath. The proctor then placed the packet outside the room (out of the participant's sight), told the participant she would be waiting outside the room and started the 30-minute cognitive load task. The proctor then stepped outside the room and partially shut the door.

After 30 minutes of the cognitive load task, an alarm rang on the computer to signal the proctor to start a stopwatch to time the dependent measure. The participant was unaware of what this alarm signified. A screen then appeared on the monitor with the phrase "The cognitive load test is complete. Thank you for participating! (this screen will not close for exactly 5 minutes)" This was to allow ample time for memory recall and execution of the prospective memory task within each participant. Once the participant recalled the task and executed the reminder for the proctor to administer the rating scale, the stopwatch was stopped and the elapsed time recorded as the participant's prospective memory performance. If the participant did not execute the prospective memory task within five minutes, 300 seconds was recorded.

However, a few participants did not explicitly remind the proctor of the rating scale after remembering to do so. An implication existed (on the participant's part) that once the participant opened the laboratory door and stated, "okay, it's over," the proctor would then administer the rating scale. If this occurred, the proctor looked confused for several moments, and then prompted with, "was there something I was supposed to do?" 
If the participant replied with, "yes, you told me to remind you of the rating scale," the prospective memory performance was recorded at the time they opened the door. If the participant replied with "I'm not sure, but I think it's over," the proctor stated "please wait until the 5 minutes are over." Several participants recalled and executed the task after receiving this cue. These participant's data were then excluded due to receiving an additional external cue.

After the participant executed the prospective memory task or once the five minutes was complete, the proctor informed the participant that he or she did not need to complete the rating scale and instead administered a demographic questionnaire. Once the questionnaire was completed, the participant was debriefed. In the debriefing, the proctor verbally asked the participant when they remembered to remind the proctor in respect to when they opened the laboratory door. If the participant replied that they did not recall the task immediately prior (any greater than $2-3$ second delay) to opening the door/notifying the proctor (or that they remembered after receiving the additional cue), the proctor then probed for reasons for the delay. This data was documented. Finally, each participant was thanked for his or her time and escorted out of the laboratory.

Results

Two-hundred seventy San Jose State University students participated in this study to examine the effects of survival-based tasks on prospective memory performance. The rationale of this examination was to determine whether prospective memory was selected for increased survival skills in the evolutionary process of cognition. Also, we examined whether prospective memory would be recalled differentially in frequency and/or 
expeditiousness under two different cognitive loads. This was performed to understand if attention is allocated differently in prospective memory depending on cognitive load level. Each participant's prospective memory performance, as well as his or her age, gender, ethnicity, college year, major, grade point average (GPA), busyness rating and stress rating, how often s/he internally reminded him/herself within the 30 -minute cognitive load task, and whether s/he immediately reminded the proctor after remembering to do so (and reasons why if not) were recorded at time of data collection.

The first set of analyses concerns the total amount of participants who completed the study. The second set of analyses evaluates participants who executed the prospective memory task immediately after recall. The last sets of analyses examine those participants whose execution was delayed in regard to recall, as well as those who failed to recall the prospective memory task within the five minute window.

\section{Full Set Demographics}

The participants in this study had a mean age of 20.38 years $(\mathrm{SD}=2.84), 70.0 \%$ were female, $30.4 \%$ were Caucasian, $44.4 \%$ were freshman, $37.8 \%$ were psychology majors, had a mean GPA of 3.15 , had a mean busyness self-report of 5.16 and stress selfreport of 4.82 (both on a 7-point scale, 7 signifying extremely busy/stressed within the past month), on average internally reminded themselves 2.09 times within the 30-minute cognitive load task, and $66.7 \%$ immediately executed the prospective memory task after recall. Means/percentages and standard deviations of all variables for each of the four groups are presented in Table 1, with overall means/percentages and standard deviations presented in Table 2. 
Table 1

Percentages, Means, and Standard Deviations of Variables for the Full Set of Participants

\begin{tabular}{|c|c|c|c|c|}
\hline & $\begin{array}{c}n=68 \\
\text { Survival High } \\
M \\
(S D)\end{array}$ & $\begin{array}{c}n=71 \\
\text { Survival Low } \\
M \\
(S D)\end{array}$ & $\begin{array}{c}n=60 \\
\text { Cultural High } \\
M \\
(S D)\end{array}$ & $\begin{array}{c}n=71 \\
\text { Cultural Low } \\
M \\
(S D)\end{array}$ \\
\hline Prospective Memory Performance & $\begin{array}{l}38.94 \\
(69.24)\end{array}$ & $\begin{array}{c}50.06 \\
(86.41)\end{array}$ & $\begin{array}{c}39.97 \\
(79.54)\end{array}$ & $\begin{array}{c}46.25 \\
(74.41)\end{array}$ \\
\hline \multicolumn{5}{|l|}{ Demographic Variables } \\
\hline Age (years old) & $\begin{array}{l}20.32 \\
(3.05)\end{array}$ & $\begin{array}{l}20.15 \\
(2.25)\end{array}$ & $\begin{array}{l}20.07 \\
(2.52)\end{array}$ & $\begin{array}{l}20.92 \\
(3.34)\end{array}$ \\
\hline \multicolumn{5}{|l|}{ Ethnicity } \\
\hline Caucasian & $33.8 \%$ & $26.8 \%$ & $38.3 \%$ & $23.9 \%$ \\
\hline African-American & $2.9 \%$ & $5.6 \%$ & $5.0 \%$ & $8.5 \%$ \\
\hline Asian-American & $32.4 \%$ & $29.6 \%$ & $15.0 \%$ & $26.8 \%$ \\
\hline S. Pacific Islander & $4.4 \%$ & $1.4 \%$ & $5.0 \%$ & $2.8 \%$ \\
\hline Latino/a & $17.6 \%$ & $18.3 \%$ & $25.0 \%$ & $25.4 \%$ \\
\hline Middle Eastern & $0.0 \%$ & $7.0 \%$ & $3.3 \%$ & $1.4 \%$ \\
\hline Other & $8.8 \%$ & $11.3 \%$ & $8.3 \%$ & $9.9 \%$ \\
\hline \multicolumn{5}{|l|}{ Year in College } \\
\hline Freshman & $42.6 \%$ & $46.5 \%$ & $46.7 \%$ & $42.3 \%$ \\
\hline Sophomore & $13.2 \%$ & $9.9 \%$ & $13.3 \%$ & $7.0 \%$ \\
\hline Junior & $20.6 \%$ & $21.1 \%$ & $21.7 \%$ & $21.1 \%$ \\
\hline Senior & $19.1 \%$ & $22.5 \%$ & $16.7 \%$ & $28.2 \%$ \\
\hline Graduate & $2.9 \%$ & $0.0 \%$ & $1.7 \%$ & $0.0 \%$ \\
\hline Psychology Major & $30.9 \%$ & $43.7 \%$ & $36.7 \%$ & $39.4 \%$ \\
\hline GPA & $\begin{array}{c}3.17 \\
(0.44)\end{array}$ & $\begin{array}{c}3.07 \\
(0.44)\end{array}$ & $\begin{array}{l}3.24 \\
(0.51)\end{array}$ & $\begin{array}{l}3.14 \\
(0.43)\end{array}$ \\
\hline \multicolumn{5}{|l|}{ Other Variables } \\
\hline Busyness Level & $\begin{array}{c}5.06 \\
(0.99)\end{array}$ & $\begin{array}{c}5.13 \\
(1.00)\end{array}$ & $\begin{array}{r}5.20 \\
(1.10)\end{array}$ & $\begin{array}{c}5.27 \\
(1.22)\end{array}$ \\
\hline Stress Level & $\begin{array}{l}4.59 \\
(1.20)\end{array}$ & $\begin{array}{r}4.79 \\
(1.35)\end{array}$ & $\begin{array}{c}5.07 \\
(1.31)\end{array}$ & $\begin{array}{c}4.86 \\
(1.32)\end{array}$ \\
\hline \# of Internal Reminders & $\begin{array}{c}1.69 \\
(1.96)\end{array}$ & $\begin{array}{c}2.66 \\
(3.68)\end{array}$ & $\begin{array}{l}2.09 \\
(4.43)\end{array}$ & $\begin{array}{r}1.94 \\
(3.40)\end{array}$ \\
\hline Immediately Remind & $66.2 \%$ & $63.4 \%$ & $75.0 \%$ & $63.4 \%$ \\
\hline
\end{tabular}




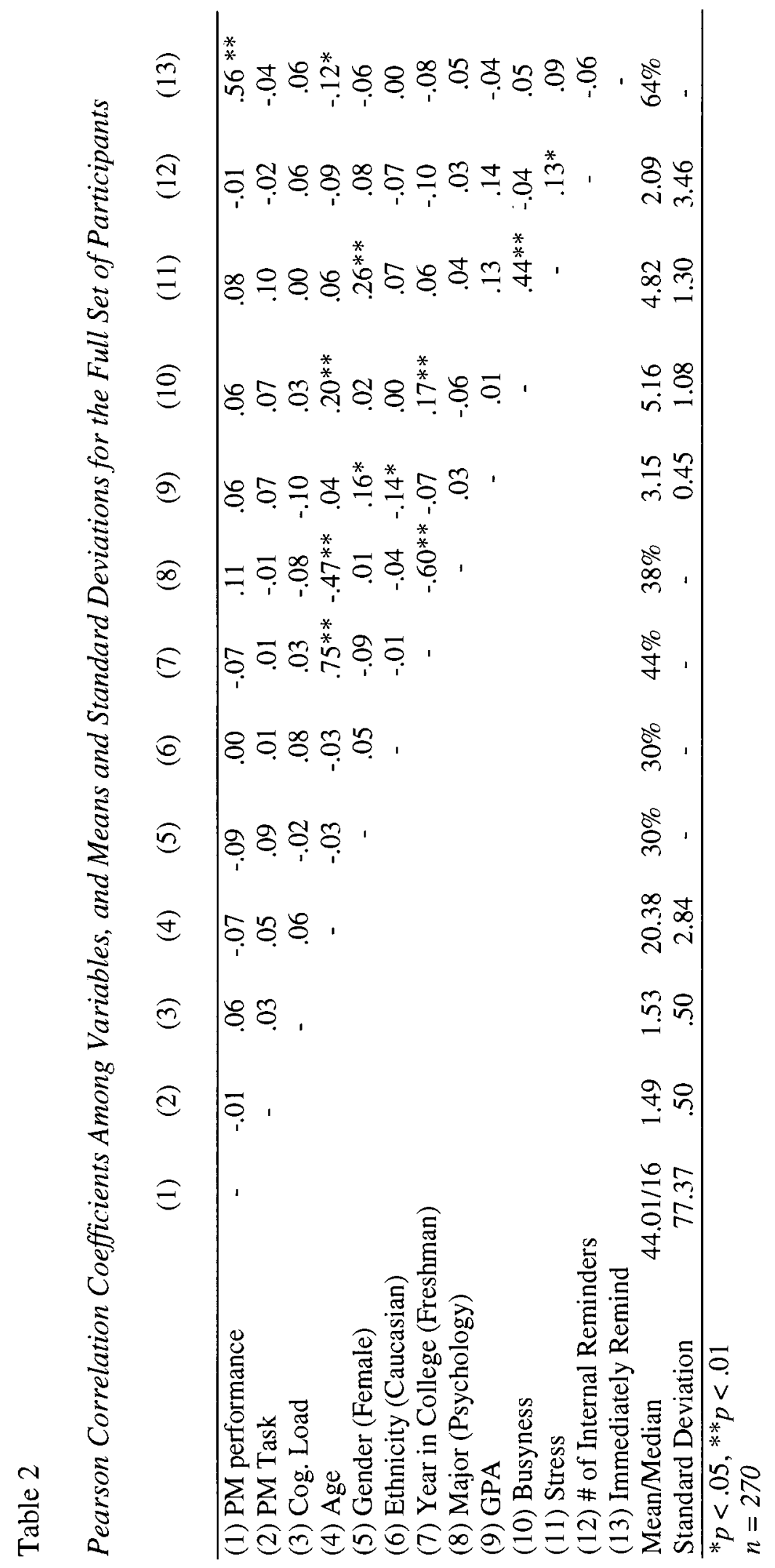




\section{Full Set Correlations}

Pearson's correlations between the demographic variables, level of cognitive load, type of prospective memory task and prospective memory performance for the full set of participants are presented in Table 2. No significant correlations between prospective memory performance correlated with any other variable except immediate reminder, (.56, $p<.01)$. This can be expected because the participants who immediately executed the task after recall had a more expeditious performance than those who did not. Age significantly correlated with year in college $(.75, p<.01)$, major $(-.47, p<.01)$, busyness rating $(.20, p<.01)$, and immediate reminder $(-.12, p=.04)$. These correlations signify that the older participants in this study were more likely to be upper-division students, psychology majors, more likely to have a higher self-report of busyness, and were more likely to immediately execute the task after recall.

Gender correlated with GPA $(.16, p=.02)$ and stress $(.26, p<.01)$, indicating that females were more likely to have a higher self-report of stress and have a higher GPA. Interestingly, the number of internal reminders positively correlated with stress rating, $(.14, p=.04)$, signifying that the participants were likely to remind themselves more often if they reported that they were more stressed within the past month. However, stress or number of internal reminders did not significantly correlate with prospective memory performance, $(.08, p=.19)$ and $(-.01, p=.87)$.

\section{Full Set Inferential Statistics}

Four groups of participant's prospective memory performance, or the number of seconds elapsed between the completion of the cognitive load task and the prospective 
memory execution (0-300 seconds), were analyzed. Each group size's full set was unequal due to differential subject mortality. The first group $(n=68)$ was asked to remind the proctor about a survival-based task after a high cognitive load, $M=38.94$ seconds, $S D=69.24, M d n=15$; the second group $(n=71)$ was asked to remind the proctor about a survival-based task after a low cognitive load, $M=50.06$ seconds, $S D=$ $86.41, M d n=17$; the third group $(n=60)$ was asked to remind the proctor about a cultural-based task after a high cognitive load, $M=39.97$ seconds, $S D=79.54, M d n=$ 14 ; the fourth group ( $n=71)$ was asked to remind the proctor about a cultural-based task after a low cognitive load, $M=46.25$ seconds, $S D=74.41, M d n=17$. With an alpha level of .05, a two-way analysis of variance (ANOVA) on the number of seconds elapsed was conducted indicating that type of prospective memory task had no significant effect on prospective memory performance, $F(1,266)=0.02, p=.88$. The standard difference (d) between marginal means for the type of prospective memory task was 0.02 .

Furthermore, the level of cognitive load did not reach significance, indicating the level of cognitive load also had no significant main effect on the expeditiousness of prospective memory performance, $F(1,266)=0.84, p=.36, d=0.11$. There was no interaction between the type of prospective memory task and cognitive load on the expeditiousness of prospective memory performance, $F(1,266)=0.07, p=.80$. Figure 1 displays the mean number of seconds elapsed as a function of the cultural-based and survival-based tasks and level of cognitive load as presented in a line graph. 


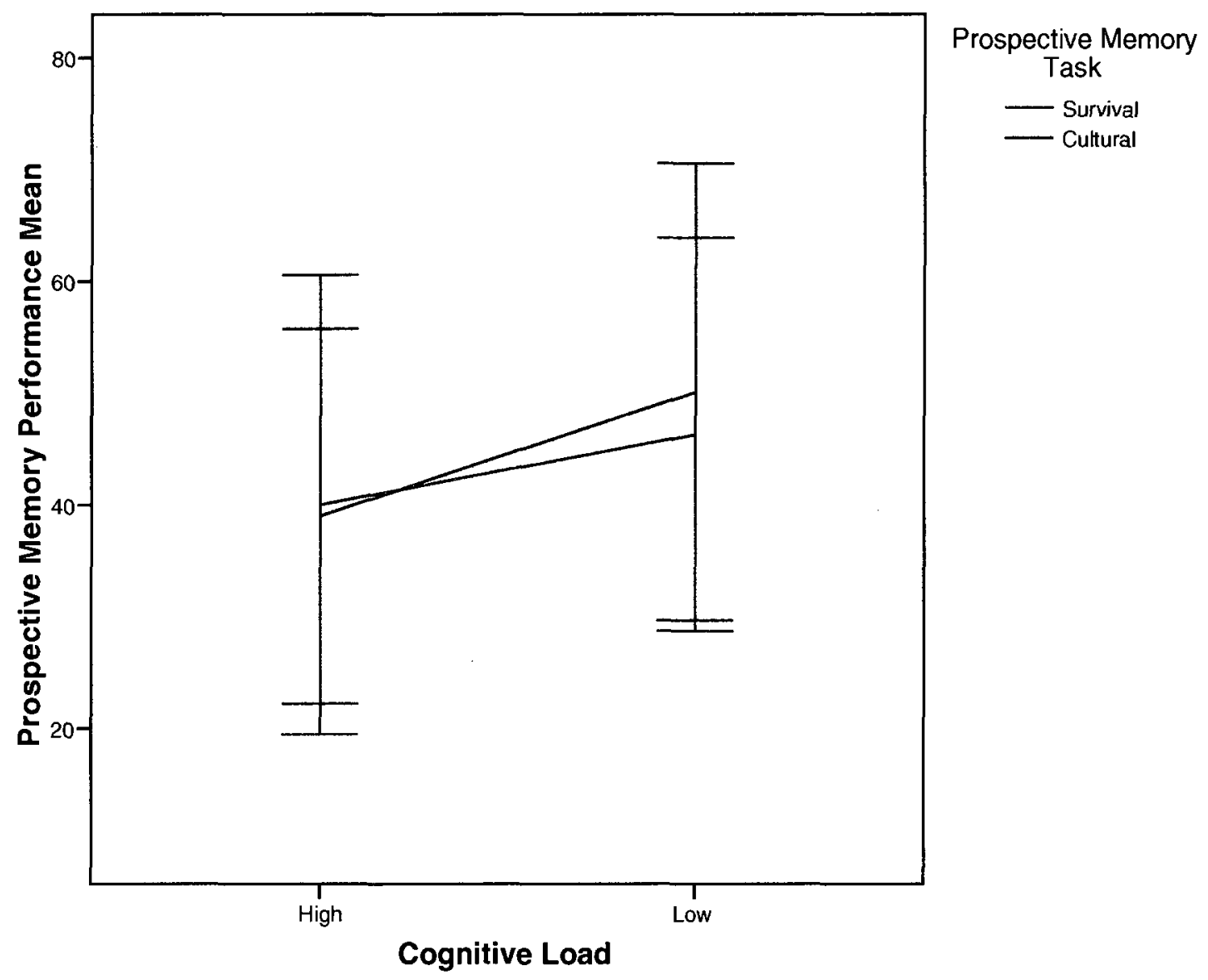

Error bars: $95 \% \mathrm{Cl}$

Figure 1

Line Graph of Mean Number of Seconds Elapsed as a Function of Cultural and Survival Tasks and Level of Cognitive Load (All Participants) 
This set includes six participants who did not recall the prospective memory task, even when cued by the proctor with "was there something I was supposed to give you?" after the 5 minute window. Despite excluding these six participants, a two-way analysis of variance (ANOVA) on the number of seconds elapsed was conducted revealing that type of prospective memory task had no significant effect on prospective memory performance, $F(1,260)=0.06, p=.80, d=0.02$, and level of cognitive load did not reach significance, indicating the level of cognitive load also had no significant main effect on the expeditiousness of prospective memory performance, $F(1,260)=1.34, p=.25, d=$ .14 .

Reason for Excluding Participants

Of these 270 participants, $180(67 \%)$ immediately executed the prospective memory task (to remind the proctor to administer the rating scale) after task recall without prompting after the 30 -minute cognitive load task. This subset is of particular interest because the primary concern of the study lies in the length of time between completion of the cognitive load task and prospective memory task recall, or recall lapse time. This study is less concerned with the participant's behavior and more concerned with their cognition - specifically, the exact time the participant recalled the prospective memory task. Unfortunately, the only method readily available was the participant's behavior: the execution of the task. This caused a somewhat imprecise measurement for a large percentage of participant's data: $33 \%$ of the participants delayed in executing the prospective memory task after recall, thus creating more variance in the data. To create a more accurate measurement within the employed method, those participants who 
reported in the debriefing that they did not execute the reminder immediately after recall (and thus failed to properly execute the prospective memory task) were excluded from the immediate execution subset. This subset of 180 participant's data is analyzed below. Immediate Execution Subset Demographics

The participants who immediately executed the prospective memory task after recall had a mean age of 20.62 years, $72.2 \%$ were female, $30.0 \%$ were Caucasian, $42.2 \%$ were freshman, $40.0 \%$ were psychology majors, had a mean GPA of 3.17, had a mean busyness self-report of 5.12 and stress self-report of 4.74 (both on a 7-point scale, 7 signifying extremely busy/stressed within the past month), and on average internally reminded themselves 2.20 times within the 30-minute cognitive load task.

Means/percentages and standard deviations of the demographic variables and prospective memory performance for each of the four groups are presented in Table 3, with overall means/percentages and standard deviations presented in Table 4. 
Table 3

Percentages, Means, and Standard Deviations of Variables of Participants Who Immediately Reminded the Proctor Concerning the Prospective Memory Task

\begin{tabular}{|c|c|c|c|c|}
\hline & $\begin{array}{c}n=45 \\
\text { Survival High } \\
M \\
(S D)\end{array}$ & $\begin{array}{c}n=45 \\
\text { Survival Low } \\
M \\
(S D)\end{array}$ & $\begin{array}{c}n=45 \\
\text { Cultural High } \\
M \\
(S D)\end{array}$ & $\begin{array}{c}n=45 \\
\text { Cultural Low } \\
M \\
(S D)\end{array}$ \\
\hline Prospective Memory Performance & $\begin{array}{c}14.27 \\
(7.27)\end{array}$ & $\begin{array}{l}15.80 \\
(8.22)\end{array}$ & $\begin{array}{l}15.80 \\
(9.14)\end{array}$ & $\begin{array}{c}27.73 \\
(36.10)\end{array}$ \\
\hline \multicolumn{5}{|l|}{ Demographic Variables } \\
\hline Age (years old) & $\begin{array}{r}20.84 \\
(3.52)\end{array}$ & $\begin{array}{l}20.58 \\
(2.26)\end{array}$ & $\begin{array}{l}20.20 \\
(2.76)\end{array}$ & $\begin{array}{l}20.84 \\
(3.50)\end{array}$ \\
\hline \multicolumn{5}{|l|}{ Ethnicity } \\
\hline Caucasian & $35.6 \%$ & $26.7 \%$ & $33.3 \%$ & $24.4 \%$ \\
\hline African-American & n $4.4 \%$ & $6.7 \%$ & $4.4 \%$ & $11.1 \%$ \\
\hline Asian-American & $28.9 \%$ & $24.4 \%$ & $17.8 \%$ & $24.4 \%$ \\
\hline S. Pacific Islander & $2.2 \%$ & $2.2 \%$ & $6.7 \%$ & $4.4 \%$ \\
\hline Latino/a & $20.0 \%$ & $20.0 \%$ & $28.9 \%$ & $22.2 \%$ \\
\hline Middle Eastern & $0.0 \%$ & $6.7 \%$ & $2.2 \%$ & $2.2 \%$ \\
\hline Other & $8.9 \%$ & $13.3 \%$ & $6.7 \%$ & $8.9 \%$ \\
\hline \multicolumn{5}{|l|}{ Year in College } \\
\hline Freshman & $37.8 \%$ & $35.6 \%$ & $46.7 \%$ & $48.9 \%$ \\
\hline Sophomore & $11.1 \%$ & $11.1 \%$ & $11.1 \%$ & $6.7 \%$ \\
\hline Junior & $26.7 \%$ & $26.7 \%$ & $20.0 \%$ & $15.6 \%$ \\
\hline Senior & $22.2 \%$ & $26.7 \%$ & $20.0 \%$ & $28.9 \%$ \\
\hline Graduate & $2.2 \%$ & $0.0 \%$ & $2.2 \%$ & $0.0 \%$ \\
\hline Psychology Major & $37.8 \%$ & $53.3 \%$ & $33.3 \%$ & $35.6 \%$ \\
\hline GPA & $\begin{array}{c}3.15 \\
(0.45)\end{array}$ & $\begin{array}{c}3.06 \\
(0.45)\end{array}$ & $\begin{array}{c}3.29 \\
(0.50)\end{array}$ & $\begin{array}{c}3.18 \\
(0.44)\end{array}$ \\
\hline \multicolumn{5}{|l|}{ Other Variables } \\
\hline Busyness Level & $\begin{array}{c}5.04 \\
(1.02)\end{array}$ & $\begin{array}{c}5.07 \\
(0.96)\end{array}$ & $\begin{array}{l}5.16 \\
(1.09)\end{array}$ & $\begin{array}{c}5.22 \\
(1.28)\end{array}$ \\
\hline Stress Level & $\begin{array}{l}4.51 \\
(1.25)\end{array}$ & $\begin{array}{c}4.76 \\
(1.48)\end{array}$ & $\begin{array}{c}4.96 \\
(1.36)\end{array}$ & $\begin{array}{c}4.73 \\
(1.30)\end{array}$ \\
\hline \# of Internal Reminders & $\begin{array}{c}1.63 \\
(2.10)\end{array}$ & $\begin{array}{c}2.93 \\
(3.86) \\
\end{array}$ & $\begin{array}{c}2.41 \\
(5.07)\end{array}$ & $\begin{array}{c}1.83 \\
(2.94)\end{array}$ \\
\hline
\end{tabular}




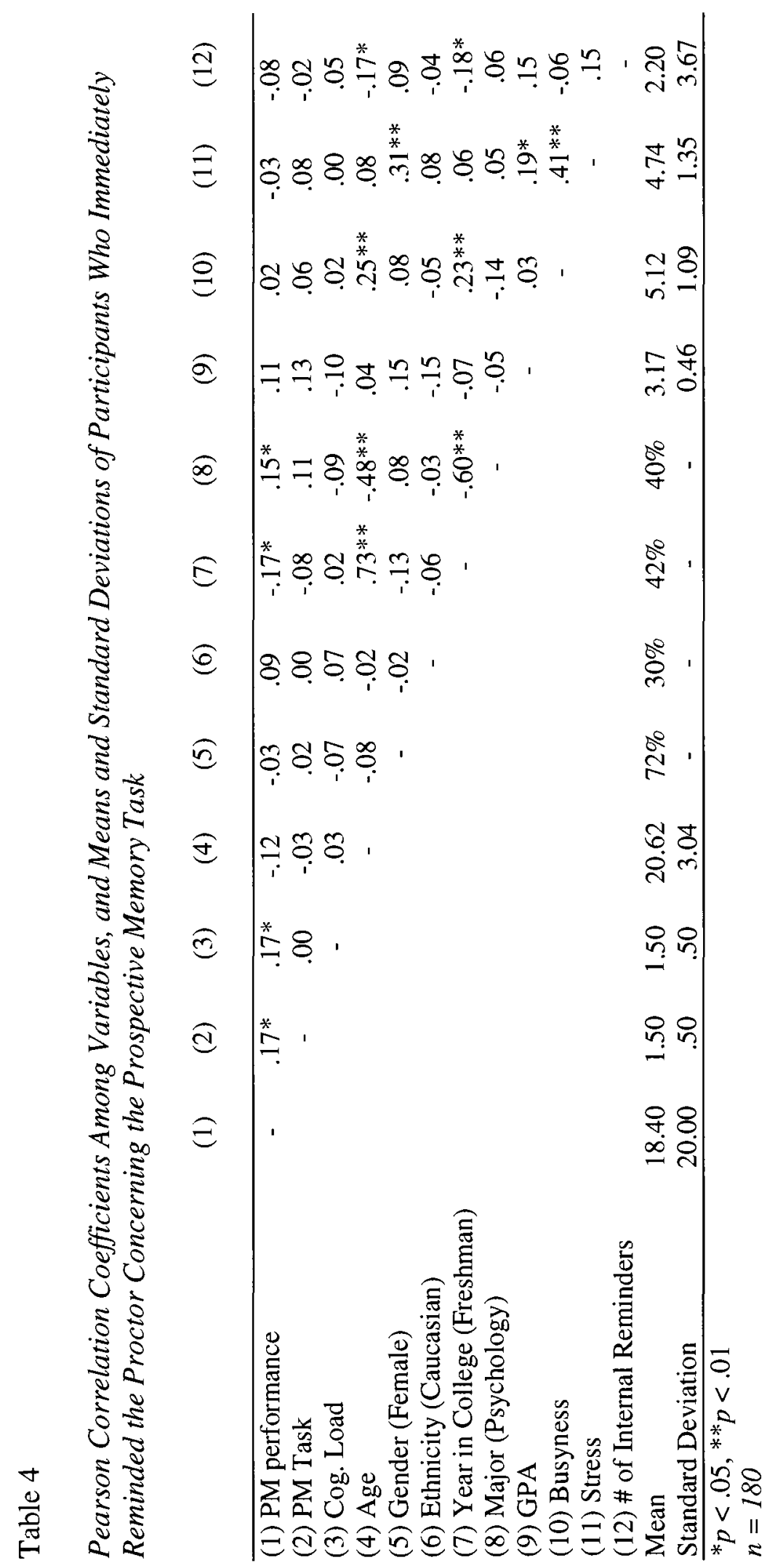




\section{Immediate Execution Subset Correlations}

For those participant's data who immediately executed the prospective memory task after recall, Pearson's correlations between the demographic variables, level of cognitive load, type of prospective memory task and prospective memory performance are presented in Table 3. Prospective memory performance correlated with type of prospective memory task $(.17, p=.02)$, as well as the level of cognitive load $(.17, p=.02)$. This indicates that in this subset, prospective memory performance was likely to be executed more expeditiously when presented with a survival-based prospective memory task and after a high cognitive load. Interestingly, prospective memory performance also correlated with college year $(-.17, p=.02)$, and major $(.15, p=.04)$. This indicates that participants who performed more expeditiously tended to be upper-division students and psychology majors. Furthermore, the frequency to which the participants reminded themselves throughout the 30 -minute cognitive load task concerning the prospective memory task negatively correlated with age $(-.17, p=.03)$ and college year $(-.18, p=.02)$. This correlation indicates that younger participants and participants who were freshman were likely to remind themselves more frequently than older participants, despite the trend that non-freshman performed more expeditiously than freshman.

\section{Immediate Execution Subset Inferential Statistics}

Four groups of 45 participant's prospective memory performance, or the number of seconds elapsed between the completion of the cognitive load task and the prospective memory execution (0-300 seconds), were analyzed. The first group was asked to remind the proctor about a survival-based task after a high cognitive load, $M=14.27$ seconds, $S D$ 
$=7.27$; the second group was asked to remind the proctor about a survival-based task after a low cognitive load, $M=15.80$ seconds, $S D=8.22$; the third group was asked to remind the proctor about a cultural-based task after a high cognitive load, $M=15.80$ seconds, $S D=9.14$; the fourth group was asked to remind the proctor about a culturalbased task after a low cognitive load, $M=27.73$ seconds, $S D=36.10$. A two-way analysis of variance (ANOVA) on the number of seconds elapsed was conducted indicating that type of prospective memory task had a significant effect on the expeditiousness of prospective memory performance, $F(1,176)=5.41, p=.02, d=0.30$. Also, the level of cognitive load reached significance, indicating the level of cognitive load also had a significant effect on the expeditiousness of prospective memory performance, $F(1,176)=5.41, p=.02, d=0.34$. There was not a significant effect in the interaction between the type of prospective memory task and cognitive load on prospective memory performance, $F(1,176)=3.23, p=.07$. Figure 2 displays the mean number of seconds elapsed as a function of the cultural-based and survival-based tasks and level of cognitive load as presented in a line graph. 


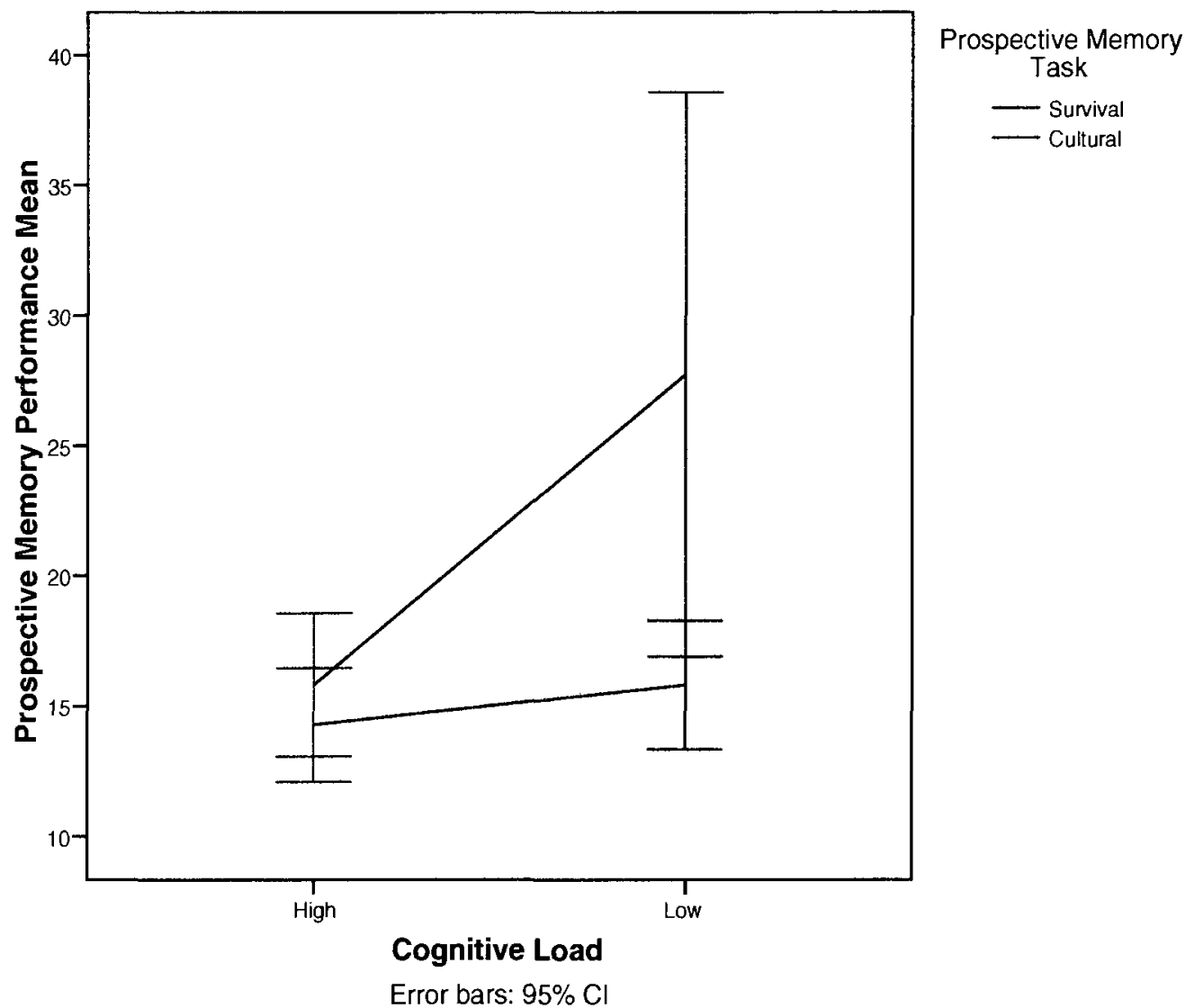

Figure 2

Line Graph of Mean Number of Seconds Elapsed as a Function of Cultural and Survival Tasks and Level of Cognitive Load (Immediate Execution Participants) 
There was a large distribution of the prospective memory performance data of the cultural-based task after a low cognitive load group compared to the other three groups. This created heterogeneity in the standard distributions (and thus ANOVA assumptions were not met); therefore, two independent samples t-tests were performed to check for significance. Analyses revealed that the type of prospective memory task was significant, $t(178)=11.12, p=.001$, as well as cognitive load level, $t(178)=2.29, p<.01$, indicating that both have a significant main effect on the expeditiousness of prospective memory performance.

\section{Excluded Participants}

Ninety participants failed to properly execute the prospective memory task (remind the proctor concerning the prospective memory task immediately after recall), and thus were excluded from the immediate execution analysis. The excluded participants were divided into three classes: participants who recalled the prospective memory task but did not immediately execute the task after recall; participants who recalled the prospective memory task after receiving an additional cue; participants who failed to recall the prospective memory task within the 5 minute window.

70 participants out of $90(78 \%)$ delayed in executing the prospective memory task. Fourteen participants (16\%) remembered the task after receiving an additional cue. The six remaining participants (7\%) failed to remember the prospective memory task.

In the survival-based task with high cognitive load group, 23 participants (26\% of the total 90) failed to properly perform the prospective memory task: 21 participants did not immediately remind the proctor after recall $(91 \%), 1$ participant executed the 
reminder after an additional cue (4\%), and 1 participant failed to recall the rating scale $(4 \%)$.

In the survival-based task with low cognitive load group, 26 participants (29\% of the total 90) failed to properly perform the prospective memory task: 20 participants did not immediately remind the proctor after recall (77\%), 4 participants executed the reminder after an additional cue (15\%), and 2 participants failed to recall the rating scale $(8 \%)$

In the cultural-based task with high cognitive load group, 15 participants (17\% of the total 90) failed to properly perform the prospective memory task: 9 participants did not immediately remind the proctor after recall (60\%), 4 participants executed the reminder after an additional cue (27\%), and 2 participants failed to recall the rating scale (13\%). This group was significantly smaller than the other three, $\chi^{2}(2)=10.79, p<0.01$. Reasons for these results are unknown.

In the cultural-based task with low cognitive load group, 26 participants (29\% of the total 90) failed to properly perform the prospective memory task: 20 participants did not immediately remind the proctor after recall (77\%), 4 participants executed the reminder after an additional cue $(15 \%)$, and 1 participant failed to recall the rating scale $(8 \%)$

\section{Delayed Execution and Additional Cued Subset Analyses}

Analyses were performed on the 84 participants who improperly executed the prospective memory task. These 84 participants were compared to the 180 participants 
who properly executed the prospective memory task to examine whether there were any factors that further differentiated the two subsets.

The participants who delayed in executing the prospective memory task or had an additional cue had a mean age of 19.94 years, $65.5 \%$ were female, $31.0 \%$ were Caucasian, $51.2 \%$ were freshman, $32.1 \%$ were psychology majors, had a mean GPA of 3.12, had a mean busyness self-report of 5.25 and stress self-report of 4.95 (both on a 7point scale, 7 signifying extremely busy/stressed within the past month), and on average internally reminded themselves 1.96 times within the 30-minute cognitive load task. Means/percentages and standard deviations of the demographic variables and prospective memory performance for each of the four groups are presented in Table 5, with overall means/percentages and standard deviations presented in Table 6.

For those participant's data who delayed in executing the prospective memory task or had an additional cue, Pearson's correlations between the demographic variables, level of cognitive load, type of prospective memory task and prospective memory performance are presented in Table 6 . The prospective memory independent variable correlated both with age, $(.26, p=.02)$ and major, $(-.25, p=.02)$. This indicates that in this subset, older participants and psychology majors were more likely assigned to the cultural task. This is due to chance because the participants were randomly assigned to the four groups. Major correlated with GPA, $(.31, p=.01)$, signifying that participants who were non-psychology majors tended to have a higher GPA. A few other correlations arose and they were similar to the immediate execution subset. 
Table 5

Percentages, Means, and Standard Deviations of Participants Who Delayed in Reminding the Proctor Concerning the Prospective Memory Task

\begin{tabular}{|c|c|c|c|c|}
\hline & $\begin{array}{l}\quad n=22 \\
\text { Survival High } \\
M \\
(S D) \\
\end{array}$ & $\begin{array}{c}n=24 \\
\text { Survival Low } \\
M \\
(S D)\end{array}$ & $\begin{array}{c}n=13 \\
\text { Cultural High } \\
M \\
(S D) \\
\end{array}$ & $\begin{array}{c}n=25 \\
\text { Cultural Low } \\
M \\
(S D) \\
\end{array}$ \\
\hline Prospective Memory Performance & $\begin{array}{c}77.55 \\
(95.25)\end{array}$ & $\begin{array}{c}93.46 \\
(113.58)\end{array}$ & $\begin{array}{c}83.62 \\
(123.59)\end{array}$ & $\begin{array}{c}69.44 \\
(99.36)\end{array}$ \\
\hline \multicolumn{5}{|l|}{ Demographic Variables } \\
\hline Age (years old) & $\begin{array}{r}19.36 \\
(1.40)\end{array}$ & $\begin{array}{l}19.42 \\
(2.17)\end{array}$ & $\begin{array}{l}19.69 \\
(1.75)\end{array}$ & $\begin{array}{l}21.08 \\
(3.15)\end{array}$ \\
\hline \multicolumn{5}{|l|}{ Ethnicity } \\
\hline Caucasian & $27.3 \%$ & $29.2 \%$ & $53.8 \%$ & $24.0 \%$ \\
\hline African-American & $0.0 \%$ & $4.2 \%$ & $7.7 \%$ & $4.0 \%$ \\
\hline Asian-American & $40.9 \%$ & $37.5 \%$ & $7.7 \%$ & $32.0 \%$ \\
\hline S. Pacific Islander & $9.1 \%$ & $0.0 \%$ & $0.0 \%$ & $0.0 \%$ \\
\hline Latino/a & $13.6 \%$ & $12.5 \%$ & $15.4 \%$ & $28.0 \%$ \\
\hline Middle Eastern & $0.0 \%$ & $8.3 \%$ & $7.7 \%$ & $0.0 \%$ \\
\hline Other & $9.1 \%$ & $8.3 \%$ & $7.7 \%$ & $12.0 \%$ \\
\hline \multicolumn{5}{|l|}{ Year in College } \\
\hline Freshman & $50.0 \%$ & $70.8 \%$ & $53.8 \%$ & $32.0 \%$ \\
\hline Sophomore & $18.2 \%$ & $4.2 \%$ & $15.4 \%$ & $8.0 \%$ \\
\hline Junior & $9.1 \%$ & $8.3 \%$ & $23.1 \%$ & $28.0 \%$ \\
\hline Senior & $13.6 \%$ & $16.7 \%$ & $7.7 \%$ & $28.0 \%$ \\
\hline Graduate & $4.5 \%$ & $0.0 \%$ & $0.0 \%$ & $0.0 \%$ \\
\hline Psychology Major & $18.2 \%$ & $25.0 \%$ & $46.2 \%$ & $44.0 \%$ \\
\hline GPA & $\begin{array}{r}3.23 \\
(0.41)\end{array}$ & $\begin{array}{c}3.05 \\
(0.40)\end{array}$ & $\begin{array}{c}3.07 \\
(0.50)\end{array}$ & $\begin{array}{c}3.10 \\
(0.40)\end{array}$ \\
\hline \multicolumn{5}{|l|}{ Other Variables } \\
\hline Busyness Level & $\begin{array}{c}5.09 \\
(0.97)\end{array}$ & $\begin{array}{c}5.13 \\
(1.04)\end{array}$ & $\begin{array}{c}5.50 \\
(1.17)\end{array}$ & $\begin{array}{c}5.40 \\
(1.12)\end{array}$ \\
\hline Stress Level & $\begin{array}{l}4.73 \\
(1.12)\end{array}$ & $\begin{array}{c}4.79 \\
(1.14)\end{array}$ & $\begin{array}{c}5.38 \\
(1.04)\end{array}$ & $\begin{array}{l}5.08 \\
(1.38)\end{array}$ \\
\hline \# of Internal Reminders & $\begin{array}{l}1.90 \\
(1.71)\end{array}$ & $\begin{array}{c}2.15 \\
(3.42)\end{array}$ & $\begin{array}{c}1.25 \\
(1.06)\end{array}$ & $\begin{array}{c}2.23 \\
(4.25)\end{array}$ \\
\hline
\end{tabular}

$n=84$ 


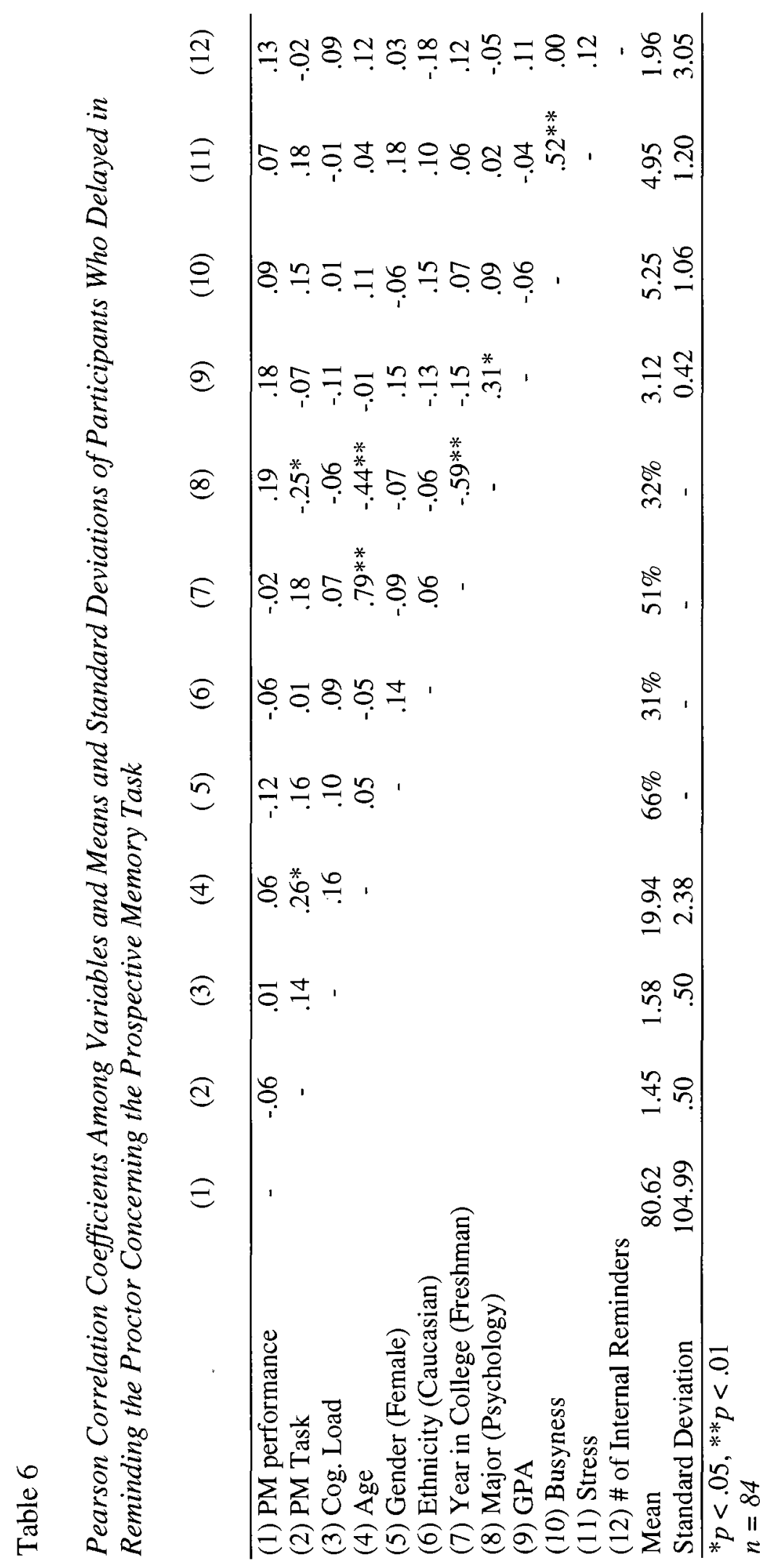


Frequency of Failed Execution

Six participants failed to recall the prospective memory task, one in the survivalbased task with high cognitive load group, two in the survival-based task with low cognitive load group, two in the cultural-based task with high cognitive load group, and one in the cultural-based task with low cognitive load group. Because they were fairly well distributed among the four groups, no further analyses were performed.

\section{Discussion}

The hypothesis of this thesis was that that prospective memory recall and immediate execution would be more expeditious when presented with a survival-based task compared to a cultural-based task. Furthermore, recall and immediate execution should be more expeditious when the task performed directly before the execution time contained a high cognitive load compared to a low cognitive load. Because of limited attention, humans are designed to process a portion of external information based on needs within their environment. Many cognitive functions evolved to systematically encode, retain and recall information that would lead to perpetuation of the individual's genes (Gaulin \& McBurney, 2001; Sweller, 2003). Information that aids in solving survival problems should be processed as more essential than other information. Therefore, higher emphasis should be placed on remembering survival-based tasks in prospective memory within a high cognitive load in which attentional resources are limited. This study found that this is true only when task execution immediately follows task recall. However, no difference was found in either task type (survival-based or cultural-based) or cognitive load level for those whose prospective memory execution is 
delayed in respect to recall. Also, there was no difference in the failure of recall frequency between the two task types or between the two cognitive load levels.

This finding is important in assisting in the understanding of the complex phenomenon of prospective memory failure. The results of this study suggest that survival-based tasks are recalled more quickly in this subsystem of memory than culturalbased tasks under both a high and low cognitive load, but may not be executed more quickly because of numerous behavioral factors. This further suggests that prospective memory adapted to have a more expeditious recall rate of survival-based tasks, but did not adapt to recall the task any more frequently than cultural-based tasks. This interpretation is highly feasible: humans adapted to remember a task more quickly when it is important to survival, but not any more frequently when compared to other tasks. If there is a less urgent need to execute that task or if there is any confusion regarding execution, then the execution expeditiousness returns to a non-survival-based task level. Further studies should be performed that provide an incentive for faster execution to further evaluate this gap between prospective memory recall and execution. However, the difference within the temporal lapse between the prospective memory cue trigger and prospective memory recall is most likely very slight between survival-based tasks and non-survival-based tasks. Therefore, any further pressure to recall and execute the tasks might wash out these effects.

The question of whether prospective memory is an adapted function or developed as an exaptation or spandrel is still unknown. This study suggests that this ability formed as an adaptation, but there are many other possible approaches that need to be considered. 
Perhaps the ability first arose as an exaptation in its inchoate form, and then was further refined by adaptive methods. In other words, perhaps this feature arose for another function or as a by-product of another feature, but continued to be altered by adaptive methods to function as it does today. Unfortunately, it would be difficult to pinpoint the exact method that this ability evolved. However, further studies surrounding cognition and evolution will uncover new theories on this topic.

\section{Cognitive Load Difficulty}

The participants executed the reminder at a more expeditious rate under the high cognitive load condition when compared to the low cognitive load condition within the immediate execution subset. This suggests that prospective memory has adapted to work well when performing other activities that require greater attention. One hypothesis for the weak performance of the low cognitive load groups is that the 30 -minute task required less vigilance and workload to perform, allowing the participant to think about other things within the 30 minutes. This might have distracted participants in recalling and executing the prospective memory task after the cognitive load task.

However, we might have seen different results if the high cognitive load task was more difficult. The high cognitive load task was substantially more difficult than the low cognitive load task; however, most participants were able to perform well in the high condition after becoming accustomed to it. If the task was more difficult and most participants were not able to perform well after some time, perhaps learned helplessness might have been introduced (Mikulincer, 1989). This might have lead to less vigilance and workload during the task, much as in the low cognitive load condition. One could 
speculate that an assumption can be made concerning the cognitive load task and prospective memory performance: prospective memory performance follows an inverted U-shaped function with level of cognitive load difficulty. This most likely extends to many other activities that occur between the encoding and execution of a prospective memory task. This might suggest that to achieve the greatest recall and execution rate of a short-term, event-based, externally-cued prospective memory task, activities between the initial prospective memory encoding and the pre-determined execution should be at a moderate difficulty rate.

\section{Prospective Memory Ratio Scale Method}

The method used to collect the dependent variable created advantages and disadvantages within this study. Ideally, it is a more sensitive measure when compared to a simple execution/no-execution measure; however, it is heavily dependent on behavior to gain accurate data. The participant needed to perform an action for this type of measure - in this case, opening a door to notify the proctor that the participant needed to complete the rating scale. However, this method does not necessarily correlate with the length of time elapsed from the completion of the cognitive load task to when the participant recalled the prospective memory task. The latter would be the preferred measurement; unfortunately, this level of measurement accuracy could not be obtained with the resources provided.

The focus of this study was less concerned with the participant's actions than their ability to cognitively recall the prospective memory task. In all prospective memory tasks, failure to execute the task would constitute as a prospective memory failure even if 
recall was present. However, the purpose of this study was to examine whether humans have adapted to recall survival-based tasks better than cultural-based tasks at the appropriate time, and if that recall would be different under two levels of cognitive load whether or not they execute that recalled task is of less importance. Unfortunately, the only possible method for this type of study with the resources available was a behavioral action: the action of execution. Therefore, this measure might be better suited to a behavioral study than a cognitive one. This measure is also less efficient and more time consuming due to discarding those participants who delayed in executing the task with respect to recall. However, the sensitivity of the ratio measurement allows for greater examination of temporal lapses.

\section{Deception}

To differentiate the recall/execution lapse time within the four groups, there was a level of deception to the study's purpose in regard to the participants. The results may have been different if the participants were made more aware of the study's purpose. The participants were lead to believe the purpose was surrounding the cognitive load task and not the prospective memory task. This was performed for two reasons. First, the participants needed to perform their best on the cognitive load task to fully engage themselves within the 30-minute time frame from initial encoding of the prospective memory task to when they were expected to recall and immediately execute that task. Second, in pilot studies preceding this study, we found that if the proctor notified the participant that is was imperative to remember the prospective memory task, there was a ceiling effect in prospective memory execution time. Almost all participants performed 
extremely well, even when the cognitive load task was 45 minutes in length. Therefore, the more causal prospective memory instructions were given to create a more natural prospective memory task and to differentiate the dependent variable among the four conditions. However, this came with difficulties: $33 \%$ of the participants delayed in executing the prospective memory task after they recalled the task.

Improper Execution and Frequency of Failed Execution

Six out of the 270 participants failed to recall the prospective memory task within the 5-minute window according to their statements in the debriefing. This proportion might have been lowered if the time frame to remember the prospective memory task was longer, perhaps 10 or 15 minutes. This time frame was arbitrary and not communicated to the participants to maintain the level of deception. Of the six participants who failed to recall the task, there is a level of uncertainty in whether they had issues with encoding or retention of the task, or if they might have recalled the task at a later time.

Not all participants who recalled the prospective memory task executed that task immediately following task recall. One third of the participants in this study delayed in executing the prospective memory task (if at all) when they had recalled the task, according to their debriefing statements. This delay was due to their behavior instead of their inability to recall the prospective memory task. Despite the proctor instructing each participant to "remind me as soon as you remember" after the cognitive load task, a large amount did not do so. When questioned during the debriefing, many of these participants stated "I remembered, but didn't remind [the proctor] right away because I thought [she] would remember" or "I remembered what to do, but not when." Also, 14 participants 
remembered after receiving an additional cue. Because of the behavioral differences between these, it is difficult to determine when the non-immediate executers recalled the task. No significant demographic differences lie between the participants who immediately executed the prospective memory task and those who delayed in executing. Perhaps the delayed executers were intimidated by the lab setting and hesitated in their execution of the prospective memory task, or because they were unsure that they were required to execute it.

\section{Issues and Future Studies}

Because of limited resources, the proctor was the researcher. This could have biased the results due to the proctor's awareness of the purpose and hypothesis of the study. For example, only a small percentage of participants increased the cultural-based task with low cognitive load group to be significantly different from the other three groups. The difference in the data from those few participants might be measurement error: the participants were asked if they recalled the task immediately before notifying the proctor in the debriefing, but perhaps they were not truthful in their responses in that one group. However, that does not explain why those participants were unproportionally weighted in that group. In future studies, all proctors should be blind to the purpose of the experiment. To provide further balancing in the design, the proctors should be gender counterbalanced and tested for reliability and consistency to provide less variance in the data.

Also in future studies, examination of the materials presented to the participants to aid in encoding of the prospective memory task needs to be performed to assure 
validity. In this study, the only examination process in the survival-based task images were that the materials were adapted from DeBruine (2004) of composite faces rated to be attractive. There was an assumption that attractiveness manipulates survival abstractions, which should then increase attention, encoding, retention, recall and execution compared to other images that are equally relevant and important. There was no examination of the cultural-based image other than the image was not popular (would introduce other variables), and did not include faces (too closely tied to the survivalbased image).

Examination of whether the survival-based and cultural-based images manipulate the appropriate cognitive affect is critical to this study: There was an assumption that different types of external cues trigger specific types of reactions and therefore alter encoding, retention and recall. In general, the amount of attention given to a particular stimulus to encode, retain and recall information is different for every stimulus and each type of situation. From an evolutionary standpoint, more attention should be placed on stimuli that will lead to a perpetuation of the individual's genes. The author assumed that images of young, opposite-gendered faces would cause participants to place more attention to that task when compared to a non-popular movie poster.

\section{Conclusion}

This study suggests that an event-based, externally-cued, short-term, prospective memory task is executed more expeditiously when the task is survival-based compared to cultural-based, but only when executed immediately after recall. Furthermore, the expeditiousness rate is increased if an activity performed between the initial encoding and 
final execution of a prospective memory task is an activity with a high cognitive load when compared to a low cognitive load (again, only when the. Because of the novelty of the methodology and the evolutionary aspect of this prospective memory study, replication studies would be very beneficial in determining whether these effects only occur under certain situations. 


\section{References}

Barnard, A. J. (2004). Hunter-gatherers in history, archaeology and anthropology. Oxford: Berg.

Bethell-Fox, C. E., \& Shepard, R. N. (1988). Mental rotation: Effects of stimulus complexity and familiarity. Journal of Experimental Psychology: Human Perception and Performance, 1, 12-23.

Buss, D. M., Haselton, M. G., Shackelford, T. K., Bleske, A. L., \& Wakefield, J. C. (1998). Adaptations, exaptions, and spandrels. American Psychologist, 53, 533548.

Cohen, J. (1992). A power primer. Psychological Bulletin, 112, 155-159.

Davidson, J. M., Chen, J. J., Crapo, L., Gray, G. D., Greenleaf, W. J., \& Catania, J. A. (1983). Hormonal changes and sexual function in aging men. Journal of Clinical Endocrinology and Metabolism, 57, 71-77.

DeBruine, L. M. (2004). Facial resemblance increases the attractiveness of same-sex faces more than other sex faces. Proceedings of the Royal Society of London B, 271, 2085-2090.

Efklides, A., Yiultsi, E., Kangellidou, T., Kounti, F., Dina, F., \& Tsolaki, M. (2002). Wechsler memory scale, Rivermead behavioral memory test, and everyday memory questionnaire in healthy adults and Alzheimer patients. European Journal of Psychological Assessment, 18, 63-77.

Einstein, G. O., \& McDaniel, M. A. (1996). Retrieval processes in prospective memory: Theoretical approaches and some new empirical findings. In M. Brandimonte, G. Einstein \& M. McDaniel (Eds.), Prospective memory: Theory and applications (115-141). New Jersey: Lawrence Erlbaum.

Enns, J. T. (2004). The thinking eye, the seeing brain: Explorations in visual cognition. New York: W. W. Norton.

Gaulin, S. J. C., \& McBurney, D. H. (2001). Psychology: An evolutionary approach. New Jersey: Prentice Hall.

Gould, S. J. (1991). Exaptation: A crucial tool for evolutionary psychology. Journal of Social Issues, 47, 43-65. 
Iran-Nejad, A., Marsh, G. E., \& Clements, A. C. (1992). The figure and the ground of constructive brain functioning: Beyond explicit memory processes. Educational Psychologist, 7, 473-492.

Kliegel, M., Martin, M., McDaniel, M. A., \& Einstein, G. O. (2004). Importance effects on performance in event-based prospective memory tasks. Memory, 12, 553-561.

Kliegel, M., Martin, M., \& Moor, C. (2003). Prospective memory and aging: Is task importance relevant? International Journal of Psychology, 38, 207-214.

Klien, S. B., Cosmides, L., Tooby, J., \& Chance, S. (2002). Decisions and the evolution of memory: Multiple systems, multiple functions. Psychological Review, 109, 306-329.

Lewis, M., Kagan, J., \& Kalafat, J. (1966). Patterns of fixation in the young infant. Child Development, 37, 331-341.

Marsh, R. L., Hicks, J. L., Cook, G. I., \& Mayhorn, C. B. (2007). Comparing older and younger adults in an event-based prospective memory paradigm containing an output monitoring component. Aging, Neuropsychology, and Cognition, 14, 168188.

Mikulincer, M. (1989). Cognitive interference and learned helplessness: The effects of off-task cognitions on performance following unsolvable problems. Journal of Personality and Social Psychology, 57, 129-135.

Nairne, J. S., Thompson, S. R., \& Pandeirada, J. N. S. (2007). Adaptive memory: Survival processing enhances retention. Journal of Experimental Psychology: Learning, Memory, and Cognition, 33, 263-273.

Ohman, A., \& Mineka, S. (2001). Fears, phobias and preparedness: Toward an evolved module of fear and fear learning. Psychological Review, 108, 483-522.

Pascalis, O., de Haan, M., Nelson, C. A., (2002). Is face-processing species specific during the first year of life? Science, 5571, 1321-1323.

Pillay, H. K. (1994). Cognitive load and mental rotation: Structuring orthographic projection for learning and problem solving. Instructional Science, 22, 91-113.

Rendell, P. G., \& Craik, F. I. M. (2000). Virtual week and actual week: Age-related differences in prospective memory. Applied Cognitive Psychology, 14, 43-62. 
Soules, M. R., Sherman, S., Parrott, E., Rebar, R., Santoro, N., Utian, W., et al. (2001). Executive summary: Stages of reproductive aging workshop (STRAW). Fertility \& Sterility, 76, 874-878.

Suddendorf, T., \& Busby, J. (2005). Making decisions with the future in mind: Developmental and comparative identification of mental time travel. Learning and Motivation, 36, 110-125.

Sweller, J. (2003). Evolution of human cognitive architecture. In B. Ross (Eds.), The psychology of learning and motivation: Advances in research and theory (215266). New York: Academic Press.

Tulving, E. (2002). Episodic memory: From mind to brain. Annual Review of Psychology, 53, 1-25.

Winograd, E. (1988). Some observations on prospective remembering. In M. Gruneberg, P. Morris, \& R. Sykes. (Eds.), Practical aspects of memory (349-353). New York: Academic Press.

Woods, S. P., Iudicello, J. E., Moran, L. M., Carey, C. L. Dawson, M. S., \& Grant, I. (2008). HIV-Associated prospective memory impairment increases risk of dependence in everyday functioning. Neuropsychology, 22, 110-117.

Zimmermann, T. D., \& Meier, B. (2006). The rise and decline of prospective memory performance across the lifespan. The Quarterly Journal of Experimental Psychology, 59, 2040-20. 
APPENDIX A: Demographics questionnaire administered to participants

\section{Demographics Questionnaire}

Age: Gender: Male Female Prefer not to answer/Other

Ethnicity: Caucasian African American Asian American South Pacific Islander Latino/Latina Middle Eastern Other

Year in college: Freshman Sophomore Junior Senior Graduate

Major Approximate GPA: (don't know/incoming freshman

About how busy would you say you have been in the past month?

$\begin{array}{ccccccc}1 & 2 & 3 & 4 & 5 & 6 & 7 \\ \text { not at all } & & & \text { moderately } & & & \text { extremely }\end{array}$
About how much stress have you been under within the past month?
1
2
3
4
5
6
7
moderately
extremely

not at all

About how often did you think of reminding the proctor to administer the rating scale packet within the 30 minutes, if at all?

Did you use anything to remind yourself to notify the proctor of the packet (e.g., write down a reminder)? If yes, what did you use?

After the mental rotation task, did you immediately remind the proctor to administer the rating scale after remembering to do so?

If your response to the previous question was no, about how long did you wait until reminding the proctor?

Thank you for participating in this study. To assist us in collecting accurate data, please do not discuss any details of this experiment with other students who might participate in the future. 
APPENDIX B: Facial attractiveness rating scale presented to all female participants in the survival-based prospective memory task condition

\section{Facial Attractiveness}
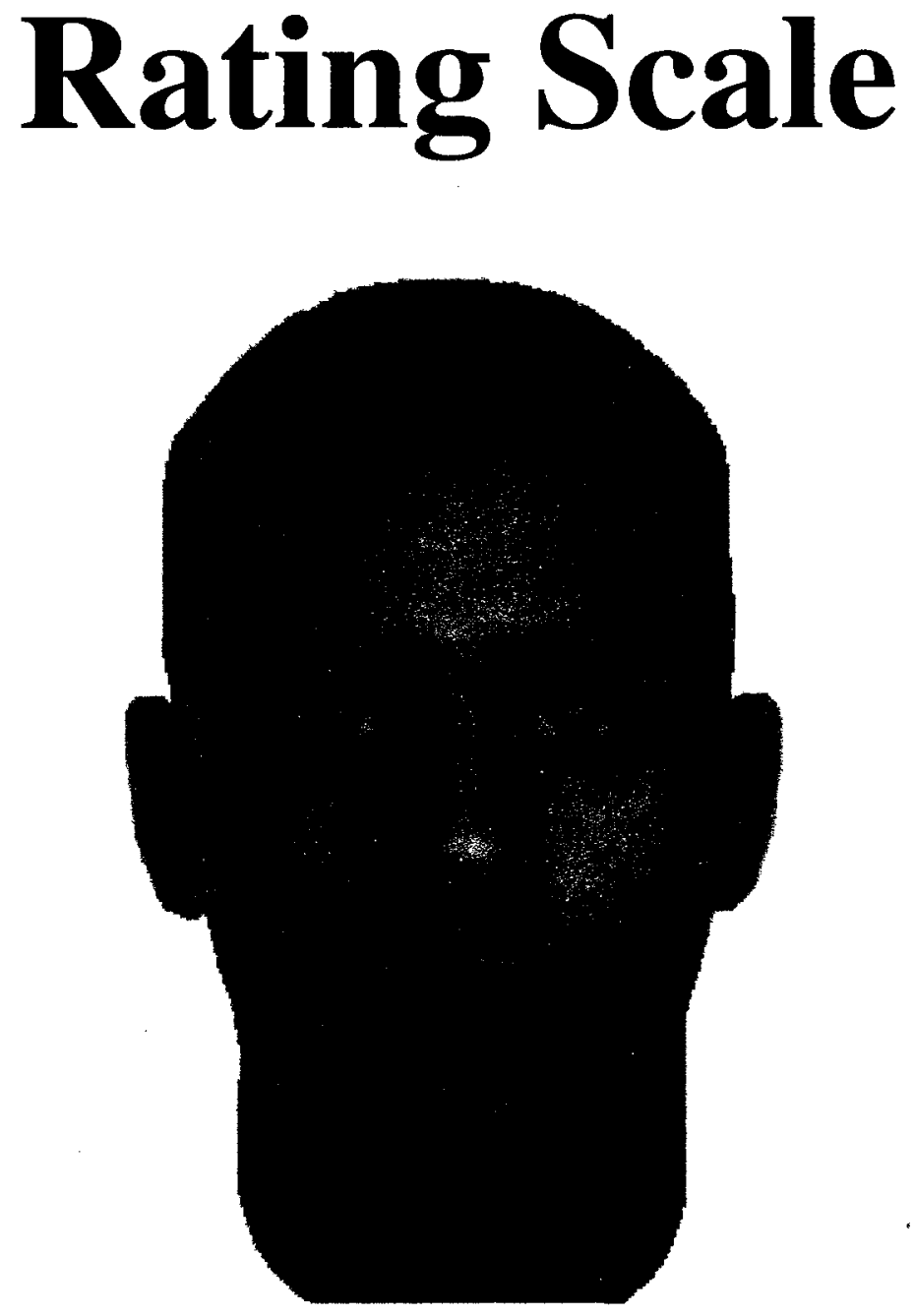

1

Not

Attractive
2

3

4

Moderately Attractive
$6 \quad 7$

Very Attractive 
APPENDIX C: Facial attractiveness rating scale presented to all male participants in the survival-based prospective memory task condition

\section{Facial Attractiveness Rating Scale}

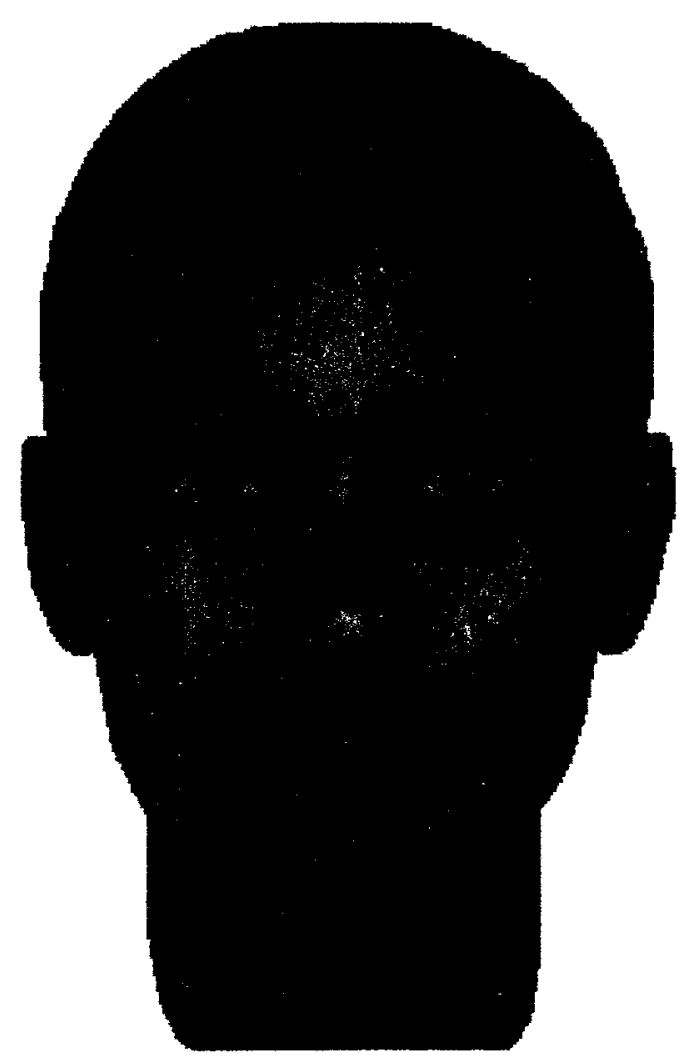

1

Not

Attractive
2

3

4

Moderately Attractive

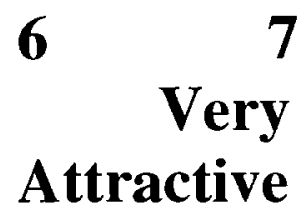

5 7 
APPENDIX D: Film preference rating scale presented to all participants in the culturalbased prospective memory task condition

\section{Film Preference} Rating Scale

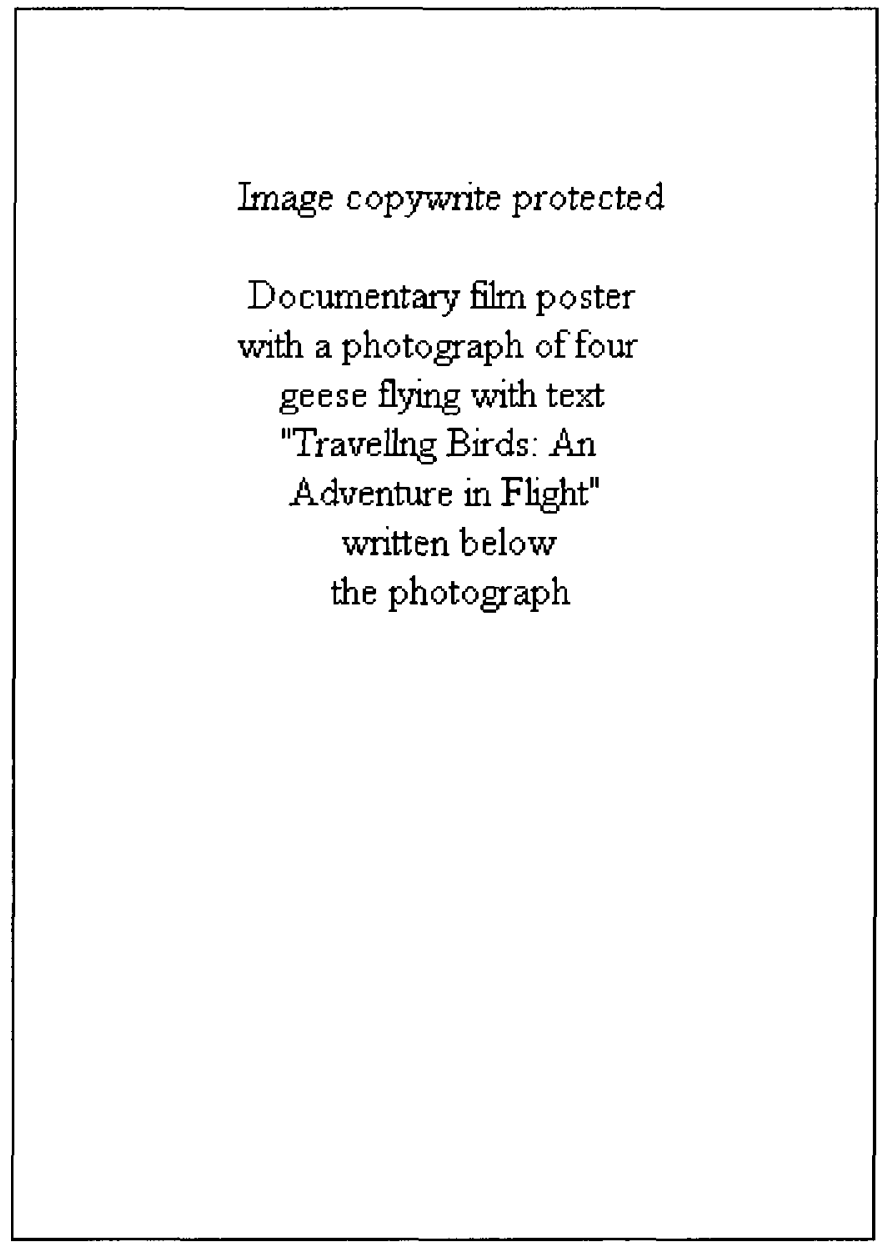

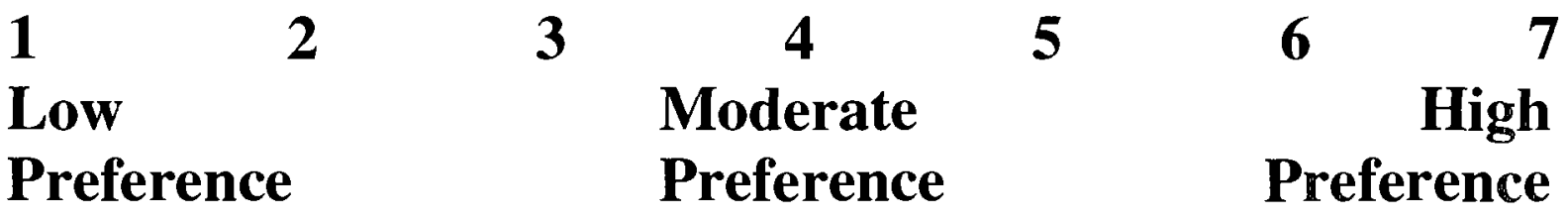


APPENDIX E: Sample of a visuospatial task series presented to participants

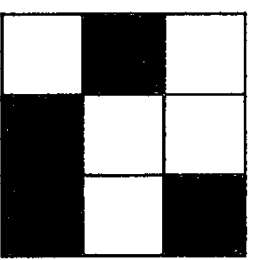

ROTATE $90^{\circ} \mathrm{CLOCKWISE}$

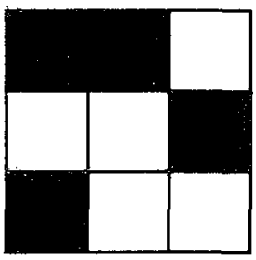

A

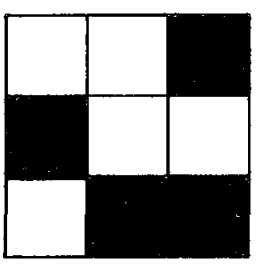

G

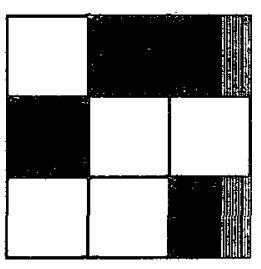

L 


\section{APPENDIX F: Letter of approval from human subjects institutional review board}

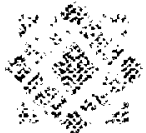

San juse state

1. $191451 \div 5$

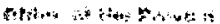

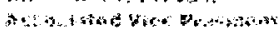

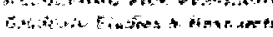

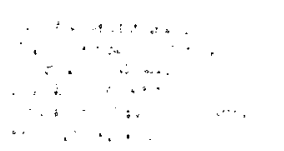

Ta: Sirall Lighta

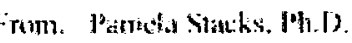

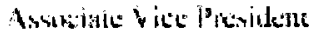

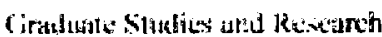

13atc; (ktuber $\bar{x}, 200 \mathrm{~B}$

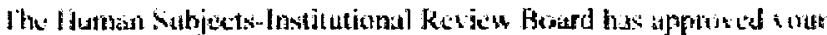
retgestes to use humben subjects in the stady tontilled:

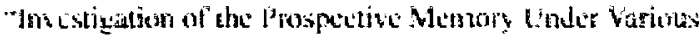
cognitive load:"

I his appnowl is contingest upon the subjects participsting in your researeh project heiteg appropriately protected from risk. I his includes the pretection of the anonymity af the subjecti jotentily when they participate

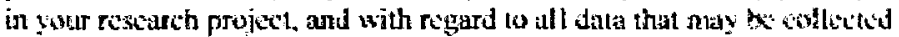
trom the subjects. The approval inclutes continued monituring of your rescard by the Board to ussure that the subjects are being adeatididy and

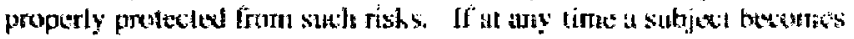

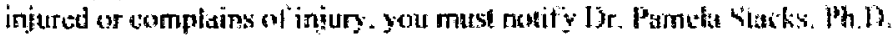
irtmediutely. Irijur includes but is not limited to hadily harrn.

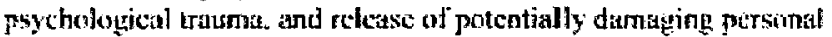

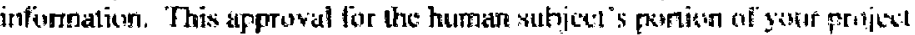

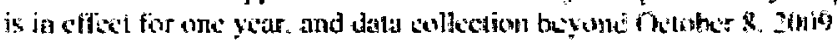
cotulires an exferasion nequest.

Please alst he advicat that all subjects net to be fully informet and

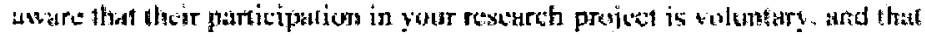
the or she mes withdrat from the stoject at any time. Further. a suticet s part wipation. relusal to purticipate. "I withdrawal will not affect any

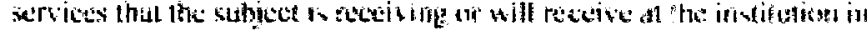
whith the reserath is heine condeluted.

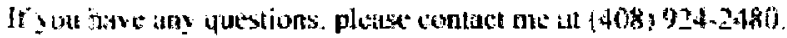

Pretucol a s0804010

(s: Kexin Jordan, 0120 